\title{
Structural Requirements of the Phytoplasma Effector Protein SAP54 for Causing Homeotic Transformation of Floral Organs
}

\author{
Marc-Benjamin Aurin,, ${ }^{1}$ Michael Haupt, ${ }^{1}$ Matthias Görlach, ${ }^{2}$ Florian Rümpler, ${ }^{1,+}$ and Günter Theißen ${ }^{1, \dagger}$ \\ ${ }^{1}$ Matthias Schleiden Institute / Genetics, Friedrich Schiller University Jena, Philosophenweg 12, 07743 Jena, Germany \\ ${ }^{2}$ Leibniz Institute on Aging - Fritz Lipmann Institute, Beutenbergstr. 11, 07745 Jena, Germany \\ Accepted 28 May 2020.
}

\begin{abstract}
Phytoplasmas are intracellular bacterial plant pathogens that cause devastating diseases in crops and ornamental plants by the secretion of effector proteins. One of these effector proteins, termed SECRETED ASTER YELLOWS WITCHES' BROOM PROTEIN 54 (SAP54), leads to the degradation of a specific subset of floral homeotic proteins of the MIKC-type MADSdomain family via the ubiquitin-proteasome pathway. In consequence, the developing flowers show the homeotic transformation of floral organs into vegetative leaf-like structures. The molecular mechanism of SAP54 action involves binding to the keratin-like domain of MIKC-type proteins and to some RAD23 proteins, which translocate ubiquitylated substrates to the proteasome. The structural requirements and specificity of SAP54 function are poorly understood, however. Here, we report, based on biophysical and molecular biological analyses, that SAP54 folds into an $\alpha$-helical structure. Insertion of helix-breaking mutations disrupts correct folding of SAP54 and compromises SAP54 binding to its target proteins and, concomitantly, its ability to evoke disease phenotypes in vivo. Interestingly, dynamic light scattering data together with electrophoretic mobility shift assays suggest that SAP54 preferentially binds to multimeric complexes of MIKC-type proteins rather than to dimers or monomers of these proteins. Together with data from literature, this finding suggests that MIKC-type proteins and SAP54 constitute multimeric $\alpha$-helical coiled coils. Our investigations clarify the structure-function relationship of an important phytoplasma effector protein and may thus ultimately help to develop treatments against some devastating plant diseases.
\end{abstract}

Keywords: $\alpha$-helical coiled coils, keratin-like domain, MADS-box gene, phyllody, phyllogen

Florian Rümpler and Günter Theißen contributed equally to this work.

${ }^{\dagger}$ Corresponding authors: G. Theißen; guenter.theissen@uni-jena.de and F. Rümpler; florian.ruempler@uni-jena.de

Funding: This work was supported by a fellowship from the International Leibniz Research School for Microbial and Biomolecular Interactions (ILRS Jena), which is part of the Jena School for Microbial Communication (to M.-B. Aurin).

*The $\boldsymbol{e}$-Xtra logo stands for "electronic extra" and indicates there are three supplementary figures and three supplementary tables published online.

The author(s) declare no conflict of interest.

๑) 2020 The American Phytopathological Society
Phytoplasmas (genus 'Candidatus Phytoplasma') are mycoplasmalike bacterial symbionts of plants belonging to the class Mollicutes. Among pathogens, they have a unique life cycle, as they invade and replicate in organisms of two different kingdoms, namely plants and animals (specifically, insects belonging to plant hoppers, leaf hoppers, and Psyllids) (Sugio et al. 2011b). Inside plants, phytoplasmas live almost exclusively within the phloem, whereas in insects they colonize most major organs, including the salivary glands from which the bacteria are transmitted to new plant hosts during feeding (Hogenhout et al. 2008; Sugio et al. 2011b). Phytoplasmas are highly derived organisms, in that they have lost their cell wall and went through massive genome reduction (Christensen et al. 2005; Firrao et al. 2007; Hogenhout et al. 2008). A phytoplasma infection may induce severe changes in plant morphology via modification of developmental processes. Morphological changes include the induction of witches' brooms (tight clustering of branches), phyllody (full or partial homeotic transformation of floral organs into leaf-like structures), virescence (green coloration of floral organs), purple top (reddening of leaves and stems), phloem necrosis, stunting of growth habit, and general yellowing of plants (Lee et al. 2000; Zhang et al. 2004). Since the plant hosts of phytoplasmas include many economically important crops, including fruit trees, and ornamental plants, these symptoms lead to economically devastating damages each year worldwide (Bertaccini 2007; Lee et al. 2000; Liu et al. 2017). Since infected plants allow the replication of phytoplasmas but are frequently not able to reproduce themselves anymore, they were termed zombie plants (Du Toit 2014).

There is evidence that phytoplasmas induce most of the developmental and morphological changes by secreting virulence factors, termed effector proteins, into the phloem of the host plant via the bacterial Sec secretion system (Bai et al. 2009; Kakizawa et al. 2001). Effectors are small peptides characterized by the presence of a signal peptide required for secretion that have been shown to reprogram plant development in several ways (Bendtsen et al. 2004; Hoshi et al. 2009; Sugio et al. 2011a). Owing to their small size, the effectors are able to travel systemically through the plant and reach tissues distant to the phloem (Bai et al. 2009; Hoshi et al. 2009; Sugio et al. 2011b).

A particularly intriguing example is the interaction of the effector protein SECRETED ASTER YELLOWS WITCHES' BROOM PROTEIN 54 (SAP54) from the 'Candidatus Phytoplasma asteris' strain aster yellows witches' broom (AY-WB), with MIKC-type MADS-domain transcription factors (MIKCtype MTFs) of the host plants (MacLean et al. 2014, 2011; Maejima et al. 2014). MTFs control a plethora of plant 
developmental processes, in angiosperms ranging from root to flower and fruit development (Smaczniak et al. 2012a; Theißen et al. 2016). Among the 45 different MIKC-type MTFs being present in the model plant Arabidopsis thaliana, only a subset is specifically bound by SAP54, most of which are involved in the control of floral meristem and organ identity (MacLean et al. 2014). SAP54 mediates the degradation of the targeted proteins via the ubiquitin-proteasome pathway (UPP) of the host plant (MacLean et al. 2014; Maejima et al. 2014, 2015). According to one model, SAP54 binds the MIKC-type MTFs in a complex together with some RADIATION SENSITIVE 23 (RAD23) proteins, which play a central role in targeting ubiquitylated proteins for proteasomal degradation (MacLean et al. 2014; Maejima et al. 2014, 2015). Since the degraded MTFs are required for the specification of organ identity during flower development, the resulting floral structures show the development of vegetative leaf-like structures rather than floral organs proper.

Within MIKC-type MTFs, SAP54 has been shown to specifically bind to the so-called keratin-like domain ( $\mathrm{K}$ domain) (MacLean et al. 2014). The K domain is shared by all MIKCtype MTFs and mediates protein-protein interactions that allow these proteins to form different homo- and heteromeric dimers and tetramers (Kaufmann et al. 2005; Melzer and Theissen 2009; Melzer et al. 2009; Puranik et al. 2014; Smaczniak et al. $2012 \mathrm{~b}$ ). The amino acid sequence within the K domain follows a characteristic pattern of regularly spaced hydrophobic and charged residues that repeats every seven amino acids (Ma et al. 1991; Riechmann et al. 1996). Such heptad repeat patterns, of the form [abcdefg] $]_{\mathrm{n}}$ with ' $\mathrm{a}$ ' and ' $\mathrm{d}$ ' positions being mainly occupied by hydrophobic amino acids, are hallmarks of $\alpha$-helical proteins folded into coiled-coil structures, a common and well-studied folding motif typical for protein-protein interaction domains (Lupas and Gruber 2005; Mason and Arndt 2004). According to X-ray crystallographic data of the MIKCtype MTF SEPALLATA3 (SEP3) from A. thaliana, which is targeted by SAP54, its K domain folds into two coiled coils separated by a short kink (Puranik et al. 2014). As the amino acid sequence within the $\mathrm{K}$ domain is highly conserved among MIKC-type MTFs, it appears very likely that the $\mathrm{K}$ domains of most MIKC-type MTFs fold into a structure very similar to that determined for SEP3 (Rümpler et al. 2018).

Based on in silico structure prediction, we previously hypothesized that SAP54 adopts a fold very similar to that of the $\mathrm{K}$ domain of MIKC-type MTFs; we also suggested that the mode of interaction between SAP54 and targeted MIKC-type MTFs resembles and mimics the one mediating protein-protein interactions among MIKC-type MTFs itself (Rümpler et al. 2015). Here, we experimentally tested these hypotheses in vitro, in vivo (yeast), and in planta using biophysical and mutational analyses as well as protein-protein interaction studies. Our data strongly corroborate the view that SAP54, indeed, folds into two $\alpha$-helices that are capable of forming a coiled coil and that are separated by a short interhelical region-all in all, a structure remarkably similar to that of the $\mathrm{K}$ domain of MIKC-type MTFs. Dynamic light scattering data and electrophoretic mobility shift assays (EMSA) suggest that this structure allows SAP54 to target MIKC-type MTFs via the formation of multimeric $\alpha$-helical coiled coils.

\section{RESULTS}

\section{In silico predictions suggest that SAP54 folds into $\alpha$-helices capable of forming coiled coils.}

To get a first impression of the structural properties of SAP54 of phytoplasma AY-WB and its homologs, we compiled a sequence collection of 28 SAP54-like proteins from a diverse set of phytoplasma strains, based on BLAST searches in the nonredundant National Center for Biotechnology Information (NCBI) nucleotide and protein collections and in wholegenome data. The vast majority of sequences aligned without any gaps (i.e., without potential insertions or deletions). With an average sequence identity of about $76 \%$, the sequences appeared to be very similar overall (Fig. 1A). Only sequences from phytoplasma strains belonging to the $16 \mathrm{SrII}$ and the 16SrXII group deviate from the majority of sequences, especially within the first 15 amino acids of the secreted part and within the center of the protein. In addition, six of the sequences appear truncated at their $\mathrm{C}$ termini. Inspection of the coding sequences (CDSs) of the respective genes revealed that either a nonsense mutation (strains 284/09 and NJAY), single or double nucleotide insertions resulting in a frame shift and a premature stop codon (strains NTU2011, PYR, and WBD), or an incomplete genomic DNA sequence (strain MA1) gave rise to the truncated sequences. Based on the aligned SAP54-like sequences, we performed secondary structure predictions applying different programs. All secondary structure prediction programs consistently predicted a high $\alpha$-helical content spanning almost the entire protein (Fig. 1B). Only the $20 \mathrm{~N}$ terminal residues appear to reside in a random coil segment. Based on most predictions, SAP5 4 comprises two putative helices that are separated by a turn or bend located at the center of the protein sequence. According to PCOILS the predicted helices show a continuous heptad repeat pattern and, consequently, a high probability to form a coiled coil. We further investigated the structure of SAP54 by conducting different folding predictions. QUARK Online, PSIPRED, and SWISSMODEL produced very similar folds, according to which SAP54 adopts a coiled-coil structure formed by two $\alpha$-helices separated by a short interhelical region (Fig. 1C). Only the SCRATCH protein predictor results deviate from the structures described above, as it predicted four short $\alpha$-helices that fold into a knot-like structure. However, given that the results of all other secondary and three-dimensional (3D) structure predictions favor the presence of two longer $\alpha$-helices (including the secondary structure prediction of SCRATCH itself), we consider the knot structure to be rather unlikely.

\section{SAP54 shows high $\alpha$-helical content.}

To experimentally address the presence of the predicted $\alpha$-helical elements of SAP54, we heterologously expressed SAP54 in Escherichia coli, purified it, and recorded circular dichroism (CD) spectra. The CD spectrum recorded for SAP54 exhibited two minima at 222 and $208 \mathrm{~nm}$, respectively, as well as a distinct maximum near $195 \mathrm{~nm}$. These features constitute hallmark spectral properties of $\alpha$-helical proteins (Fig. 2A) (Kelly et al. 2005; Ranjbar and Gill 2009). Estimated from the residual ellipticity at $222 \mathrm{~nm}$, SAP54 contains an $\alpha$-helical content of about $71 \%$ at the experimental conditions used (Table 1). In contrast, no obvious $\beta$-strand content and only minor irregular structural features were determined, likely to indicate the presence of loops or disordered regions. In order to monitor the temperature dependence of the folding state of SAP54, its molar ellipticity at 200 and $222 \mathrm{~nm}$ was determined for increasing temperatures, beginning at $20^{\circ} \mathrm{C}$ and in $5^{\circ} \mathrm{C}$ intervals to up to $90^{\circ} \mathrm{C}$. Results were visualized according to Uversky (2002). This allows assessment of the folding state of a protein for the chosen temperatures. At $20^{\circ} \mathrm{C}$, SAP54 appears in the region for folded proteins (Supplementary Fig. S1) with gradual loss of secondary structure content as the temperature is increased. At 80 to $90^{\circ} \mathrm{C}$, SAP54 appears to adopt a 'molten globule' state, which would suggest that it does not entirely denature, even at $90^{\circ} \mathrm{C}$ (Supplementary Fig. S1; Supplementary Table S1). Upon subsequently reducing the temperature back to 
A
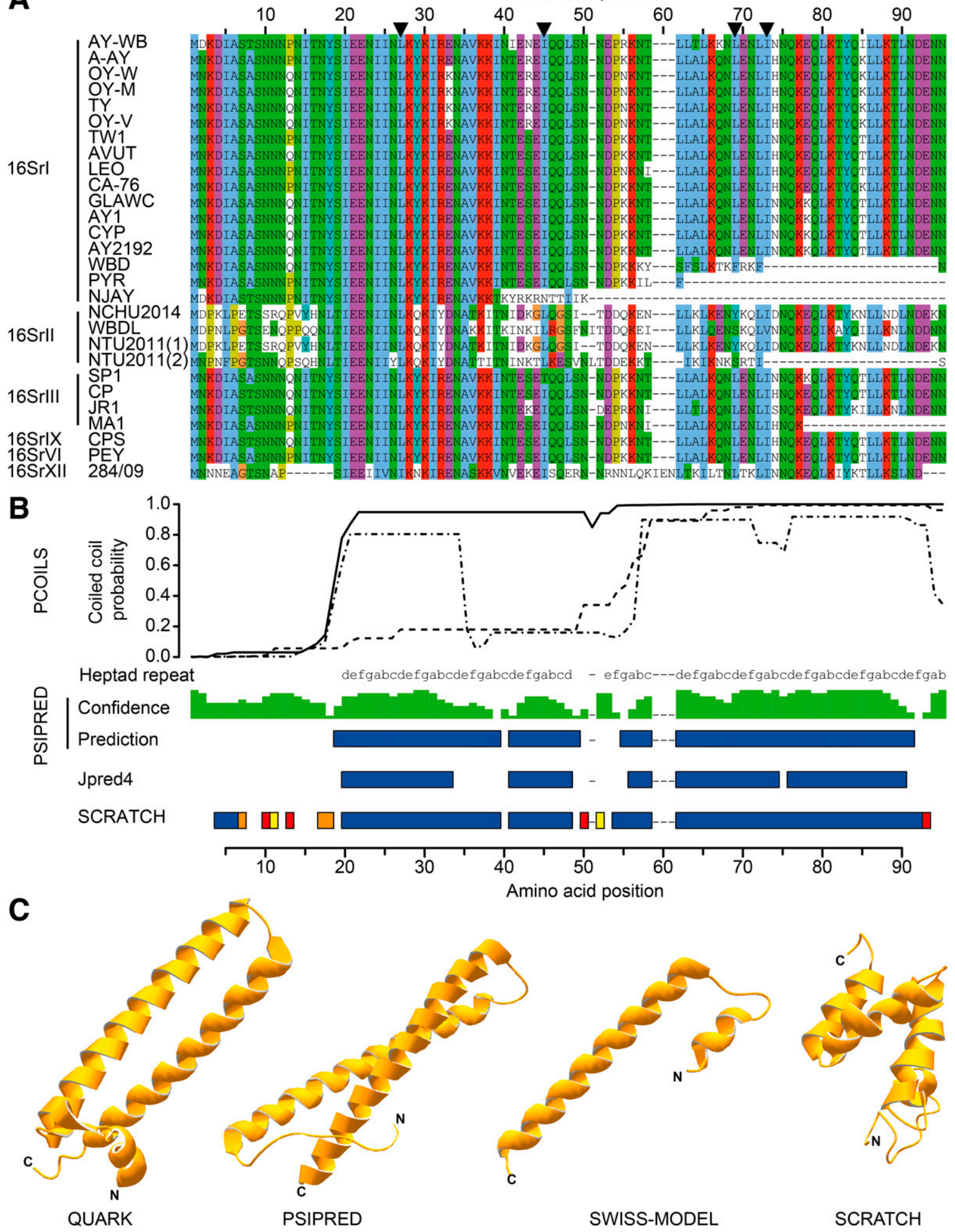

Fig. 1. Sequences and predicted structural features of SAP54-like proteins (phyllogens). A, Amino acid alignment of the secreted part of SAP54-like sequences from different phytoplasma strains. Sequences were aligned with MAFFT, applying L-INS-I mode. Black triangles on top of the alignment highlight the amino acid positions of SAP54 from AY-WB that were substituted by site-directed mutagenesis. SAP54 homologs PHYL1 $1_{\text {OY }}$ from onion yellows phytoplasma and PHYL1 $_{\mathrm{PnWB}}$ from peanut witches' broom phytoplasma, that have been recently crystallized can be found under the synonyms OY-W and NTU2011 (1), respectively. B, Secondary structure predictions based on the amino acid sequence of SAP54 from AY-WB (using Jpred4 and SCRATCH protein predictor) and the multiple sequence alignment shown in A (using PCOILS and PSIPRED). PCOILS: Dotted, dashed, and solid lines show the coiled coil probability of the amino acid alignment in A for a sliding window size of 14, 21, and 28 amino acids, respectively. PSIPRED, Jpred4, and SCRATCH: Colored boxes indicate high probability for the formation of an $\alpha$-helix (blue), extended strand (orange), turn (red), or bend (yellow), respectively. The green bar plot depicts the confidence of the PSIPRED prediction. C, Three-dimensional structure predictions for SAP54 from AY-WB, using QUARK Online, PSIPRED, SWISSMODEL, and SCRATCH protein predictor. The SWISS-MODEL prediction only comprises the C-terminal part of SAP54 (residues 43 to 91 ). 
$20^{\circ} \mathrm{C}$, SAP54 renatures to a certain degree, albeit not to its initial folded state (Supplementary Fig. S1).

\section{Truncation of putative helices results in a loss of SAP54 interaction ability.}

The vast majority of our in silico analyses suggest that the high $\alpha$-helical content of SAP54 probably involves two helices that are separated by a turn or bend located near the center of the protein sequence (Fig. 1B and C). Thus, we investigated whether deletions of either of the putative helices interferes with the interaction capabilities of SAP54 with its known MIKC-type MTF targets. As different programs predicted slightly different extents of the helices, we defined the last heptad repeat d position of the first putative helix (L48) and the first heptad repeat d position of the second helix (L59) as C terminus of helix 1 and $\mathrm{N}$ terminus of helix 2, respectively. We generated truncated versions of SAP54 in which the first predicted helix (residues 1 to 48 of the mature SAP54 [Fig. 3A]), the putative turn region (residues 49 to 58), or the second predicted helix (residues 59 to 91) were missing and tested the interaction capabilities of SAP54 wild type (SAP54-wt) and the truncated proteins in yeast two-hybrid $(\mathrm{Y} 2 \mathrm{H})$ experiments. In
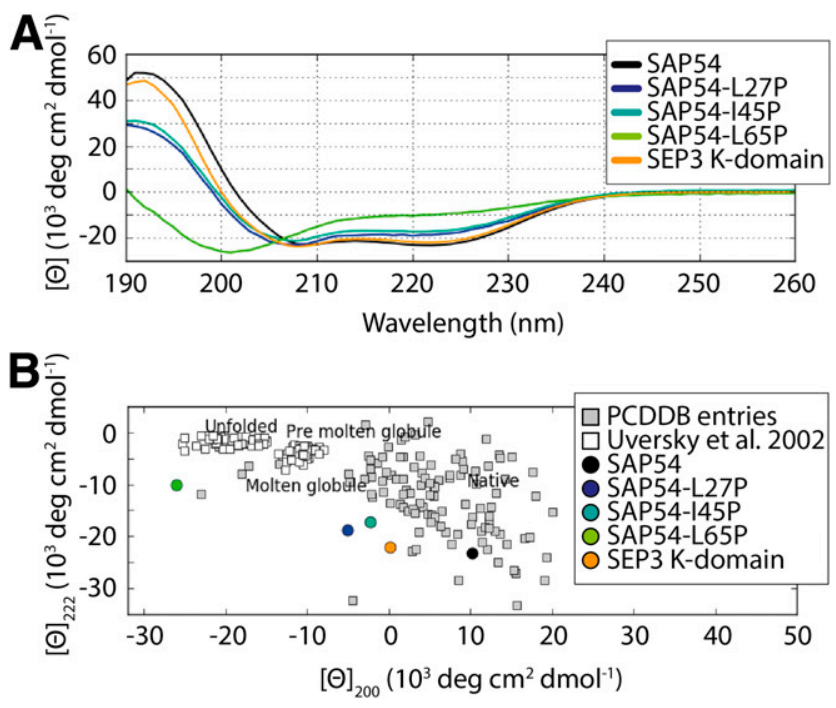

Fig. 2. Circular dichroism (CD) spectra of SAP54-wt, its mutated versions, and the K domain of SEP3. A, CD spectra recorded on a JASCO J-715 spectropolarimeter for SAP54-wt, SAP54-L27P, SAP54-I45P, and SAP54L65P and the $\mathrm{K}$ domain of SEP3 at $20^{\circ} \mathrm{C}$ in $20 \mathrm{mM}$ sodium phosphate buffer, $\mathrm{pH} 8.0$, wavelength range of 190 to $280 \mathrm{~nm}$ at 1-nm intervals and a speed of $20 \mathrm{~nm} /$ minute, using a cuvette of $1 \mathrm{~mm}$ path length. Protein concentrations were SAP54-wt, $20.7 \mu \mathrm{M}$; SAP54-L27P, $6.5 \mu \mathrm{M}$, SAP54I45P, $10.6 \mu \mathrm{M}$; SAP54-L65P, $9.9 \mu \mathrm{M}$. Each spectrum represents an accumulation of five scans, followed by background correction. B, Visualization of spectral properties of the examined proteins in the Uversky plot, which allows a categorization of the folding state for the different proteins. Graphics generated with the help of CAPITO.

Table 1. Secondary structure content of SAP54-wt, single amino acid substitution mutants, and the K domain of SEP3 ${ }^{\mathrm{a}}$

\begin{tabular}{|c|c|c|c|}
\hline Proteins & $\% \alpha$-helix & $\% \beta$-strand & $\%$ Irregular \\
\hline SAP54 & $71 \pm 9$ & $1 \pm 0$ & $29 \pm 2$ \\
\hline SAP54-L27P & 42 & 1 & 55 \\
\hline SAP54-I45P & 53 & 1 & 52 \\
\hline SAP54-L65P & 7 & 1 & 82 \\
\hline SEP3 K domain & 65 & 1 & 46 \\
\hline
\end{tabular}

a Values were calculated with CAPITO, based on the recorded circular dichroism spectra in sodium phosphate buffer, at $\mathrm{pH} 8.0$, at $20^{\circ} \mathrm{C}$. SAP54wt values represent means based on three biological replicates. accordance with previous results (MacLean et al. 2014), SAP54-wt specifically interacted with the MIKC-type MTFs SEP3, APETALA1 (AP1), and AGAMOUS-LIKE6 (AGL6) from $A$. thaliana but not with their paralogs APETALA3 (AP3), PISTILLATA (PI), and AGAMOUS (AG) (Fig. 3B and C). Deletion of either one of the two putative helices resulted in the complete loss of interaction of SAP54 (Fig. 3B and C). In contrast, deletion of the predicted turn in the center of the protein did not change its interaction behavior, which would be consistent with the hypothesized modular domain architecture of SAP54 (Fig. 3B and C). In addition to the deletions mentioned above, we also truncated the $\mathrm{C}$-terminal 11 amino acids of the second $\alpha$-helix (residues 81 to 91). Interestingly, this SAP54 $\Delta 81-91$ exhibited failure to interact with all investigated MTFs, suggesting the presence of an essential interaction element in the deleted sequence. Inspection of the C-terminal 11 amino acids in the multiple sequence alignment of SAP54-like
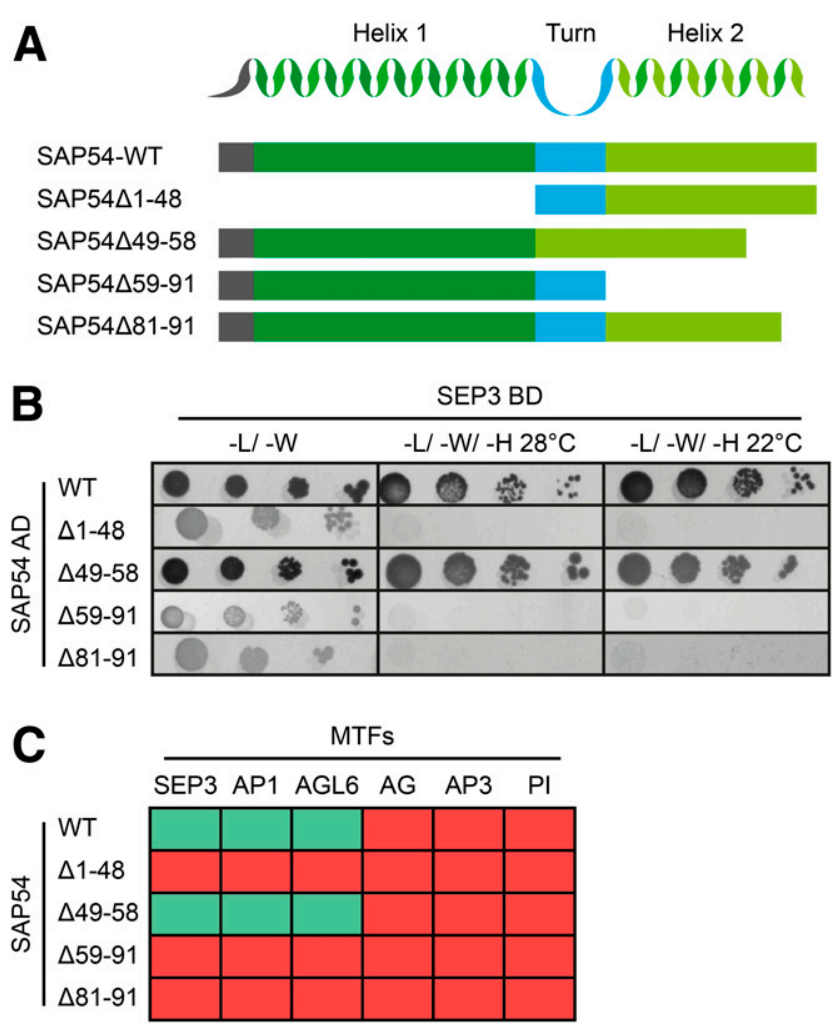

Fig. 3. Interaction of truncated SAP54 mutants with MIKC-type MADS-domain transcription factors (MTFs) in yeast two-hybrid (Y2H) experiments. A, Schematic of the deletion constructs. The presumably unstructured $\mathrm{N}$ terminus, the first predicted helix, the putative turn region, and the second predicted helix are depicted in gray, dark green, blue, and light green, respectively. B, Y2H interaction screen of SAP54-wt and truncation mutants fused to the activation domain (AD) against SEP3 fused to the binding domain (BD). Normal growth of yeast was controlled on SD-Leu-Trp plates (-L/-W). Interactions were tested on SD-Leu-Trp-His plates with $3 \mathrm{mM} 3$-amino-1,2,4-triazole $(-\mathrm{L} /-\mathrm{W} /-\mathrm{H})$ at two different temperatures $\left(28\right.$ and $\left.22^{\circ} \mathrm{C}\right)$ and in four dilutions $(1: 10,1: 100,1: 1,000$, and $1: 10,000)$. C, Summary of Y2H results for SAP54-wt and truncation mutants against SEP3, AP1, AGL6, AG, AP3, and PI. Each protein pair was tested twice in both directions (i.e., fused to the GAL4 AD and the DNA $\mathrm{BD}$ ). A combination was scored as 'interacting' (green) if yeast growth was observed for at least one direction. In contrast to previous studies (de Folter et al. 2005; Immink et al. 2009), no autoactivation capacity of SEP3 was observed if fused to the GAL4 DNA BD under our conditions. Solely AGL6-BD and AP1-BD showed very weak autoactivation in one of the two replicates. The brightness difference between colonies of interacting and noninteracting protein pairs in B is the result of a faint yellow coloration that we occasionally observed for colonies expressing interacting protein pairs. 
proteins revealed the presence of three highly conserved hydrophobic residues (L81, L82, L85) and three highly conserved charged residues (K83, D87, E88) that can be found in almost all SAP54-like proteins at homologous sites (Fig. 1A). Immunoblotting analyses (Western blot) demonstrated that all truncated SAP54 proteins are expressed in yeast (Supplementary Fig. S2), indicating that the absence of yeast growth in the above-mentioned $\mathrm{Y} 2 \mathrm{H}$ studies is attributable to the failure of the respective SAP54 derivatives to interact with MIKC-type MTFs, rather than to their expression level.

\section{Helix breaking point mutations impair the interaction ability of SAP54.}

To further analyze the importance of the $\alpha$-helical elements of SAP54 for supporting interaction with MIKC-type MTFs, individual amino acids at positions a and $\mathrm{d}$ of the heptad repeat of the proposed helices were substituted by proline residues. Proline was chosen for helix-breaking properties, as its cyclic side chain structure causes steric conflicts in a helical chain conformation (Nilsson et al. 1998; Richardson 1981). We created four individual proline substitution mutants for L27, I45, L65, and I69, respectively. Whereas L27, L65, and I69 are located close to the center of putative helix one and two, respectively, the substitution $\mathrm{I} 45$ is located at the $\mathrm{C}$ terminus of the first putative helix and close to the predicted turn region (Fig. 1A). CD spectra were recorded for purified SAP54-L27P, SAP54-I45P, and SAP54-L65P, as described above, to determine their respective secondary structure content. As expected, mutants SAP54-L27P and -L65P showed a significant reduction of $\alpha$-helical content (Fig. 2A; Table 1). In case of the L65P substitution, the formation of helical structures was almost completely abolished and analysis of SAP54-L65P in the 'Uversky plot' indicated that the protein was probably entirely unfolded (Fig. 2B). Interestingly, the substitution of isoleucine by proline at position I45 (I45P) showed the mildest reduction of $\alpha$-helical content (Table 1). Y2H analyses revealed that SAP54-L27P, SAP54-L65P, and SAP54-I69P, all expressing well in yeast, were unable to interact with any of the investigated MIKC-type MTFs (Fig. 4A and B). In contrast, SAP54-I45P was still able to interact with SEP3 and AP1, whereas the interaction with AGL6 was lost.

In order to distinguish whether the altered interaction behavior of the proline substitution mutants was, indeed, related to the helix-breaking properties of proline or if the substitution sites simply constitute crucial interaction sites, we additionally substituted all investigated amino acid positions by alanine (L27A, I45A, L65A and I69A). Similar to leucine and isoleucine, alanine has a high helical propensity and, thus, would not be expected to interfere with helix formation (Kükenshöner et al. 2014; Mason et al. 2009; Moitra et al. 1997). However, due to its small side chain, substitutions to alanine would presumably abrogate specific residue-residue interactions at the respective sites (Cunningham and Wells 1989; Morrison and Weiss 2001). In contrast to the respective proline substitutions, all alanine substitution mutants were still able to interact with the known MIKC-type MTF targets of SAP54 (Fig. 4A and B). Only SAP54-L27A lost the ability to interact with AGL6 (Fig. 4B). Western blot analyses revealed that all SAP54 mutant proteins had been produced in full length in yeast (Supplementary Fig. S2).

\section{SAP54 mutants with disturbed helix formation are unable to cause disease phenotypes.}

To investigate the importance of the $\alpha$-helical structure of SAP54 for its ability to cause disease phenotypes, we overexpressed SAP54-wt and mutant versions under the control of the cauliflower mosaic virus (CaMV) $35 \mathrm{~S}$ promoter in $A$. thaliana
Columbia-0 (Col-0). In accordance with previous results (MacLean et al. 2014), overexpression of SAP54-wt caused phyllody, i.e., the homeotic transformation of floral organs into vegetative leaf-like structures, and a partial loss of floral determinacy (Fig. 4C). Furthermore, we observed clusters of undifferentiated cells arising from inflorescence meristems-a phenotype partially resembling the cauliflower-like appearance of a cauliflower (cal), apl double mutant (Kempin et al. 1995). When SAP54-L27P, SAP54-L65P, and SAP54-I69P, which encode for proline substituted positions close to the center of the putative helices, were overexpressed, no phenotypic alterations were observed with flowers developing to be wild type-like through anthesis (Fig. 4D, F, and G). In contrast, floral abnormalities were observed when overexpressing SAP54-I45P that encodes for a proline substitution close to the putative turn region, although the phenotypic alterations were weaker than those for SAP54-wt (Fig. 4E). Plants overexpressing SAP54-I45P developed flowers in which most floral organs were replaced by leaf-like structures; however, some flowers developed a few petals and stamens (Fig. 4E). Overexpression of the alanine substitution mutants SAP54-L27A, SAP54-L65A, and SAP54-I69A resulted in mutant phenotypes similar to those observed for plants overexpressing SAP54-wt (Fig. 4H through J). To ensure that absence of phenotypic alterations was due to the inability of respective SAP54 derivatives to interact with MIKC-type MTFs and not due to their absence, expression of SAP54 proteins in planta was confirmed by Western blot analysis (Supplementary Fig. S2).

\section{SAP54 preferentially targets multimers of MIKC-type MTFs.}

In light of the high structural similarity between SAP54 and the K domain of MIKC-type MTFs, we aimed to investigate the stoichiometry of a SAP54/K-domain complex. Therefore, we performed dynamic light scattering analyses of purified SAP54 in the presence of purified $\mathrm{K}$ domain of SEP3 $\left(\mathrm{SEP}^{75-178}\right.$ ) at different molar ratios. SAP54 in the absence of SEP3 K domain produces single peaks at an average hydrodynamic radius of $2.17 \pm 0.12 \mathrm{~nm}$, indicating an average molecular mass estimate of about $20 \pm 2 \mathrm{kDa}$. This suggests that SAP54 forms homodimers at a concentration of $50 \mu \mathrm{M}$ under the experimental phosphate buffer conditions (Fig. 5A; Table 2).

SEP3 ${ }^{75-178}$ alone shows one peak that corresponds to a single protein population with a hydrodynamic radius of $3.32 \mathrm{~nm}$, corresponding to an estimated molecular mass of an approximately $56-\mathrm{kDa}$, globularly shaped protein. According to previous results (Puranik et al. 2014), the observed peak very likely represents a SEP $3^{75-178}$ homotetramer, although the calculated mass of a tetramer would be slightly lower (approximately $48 \mathrm{kDa}$ ). If SAP54 and SEP3 ${ }^{75-178}$ were mixed in molar ratios of 1:5, 1:2, and $1: 1$, single peaks at $3.35,3.43$, and $3.38 \mathrm{~nm}$, respectively, were observed corresponding to almost identical molecular masses of approximately 58, 61, and $59 \mathrm{kDa}$ (Fig. 5A; Table 2). As we observed only a single peak for all protein ratios, it appears likely that SAP54 and SEP3 ${ }^{75-178}$ form heteromeric complexes of the determined size. Otherwise an additional peak at around $2 \mathrm{~nm}$ would be expected, which represents SAP54 protein that was not incorporated into a heteromeric complex. Due to the potential influence of complex shape on the mass estimate and the similar size of SAP54 and SEP3 ${ }^{75-178}$, it cannot be ruled out that the observed peaks at approximately $3.4 \mathrm{~nm}$ may be produced by a mixture of complexes of different composition but very similar mass (e.g., a SEP3 $3^{75-178}$ homotetramer and a SEP3 ${ }^{75-178} /$ SAP54 heteropentamer). However, according to our data, it appears likely that, up to a molar ratio of 1:1, SAP54 and SEP3 ${ }^{75-178}$ form complexes that consist of four to five proteins, whereby the ratio of SAP54 and SEP $3^{75-178}$ proteins within these complexes might 
be variable. If the amount of SAP54 was increased further to molar ratios of $2: 1$ and $5: 1$, single peaks at $3.01 \mathrm{~nm}$ (corresponding to approximately $45 \mathrm{kDa}$ ) and $2.53 \mathrm{~nm}$ (approximately $30 \mathrm{kDa}$ ) were observed (Fig. 5A; Table 2). Thus, higher concentrations of SAP54 seem to break up these complexes and, instead, apparently favor the dynamic formation of heteromultimers of varying composition.

To test whether SAP54 indeed tends to bind to multimers of MIKC-type MTFs, at least at low ratios of SAP54 to MIKCtype MTFs, we modified a previously established EMSA in order to conduct so-called supershift experiments. If in vitrotranslated SEP3 full-length protein was co-incubated with a radioactively labeled DNA probe that carries two MIKC-type MTF DNA-binding sites (so called CArG-boxes), a single retarded fraction appeared close to the $1-\mathrm{kb}$ fragment of the DNA marker (Fig. 5B, lane 1). As has been demonstrated in several previous studies, this fraction constitutes a SEP3 tetramer bound to both DNA-binding sites via looping the DNA in between both binding sites (Jetha et al. 2014; Melzer et al. 2009; Rümpler et al. 2018). When purified SAP54 was added to the

A

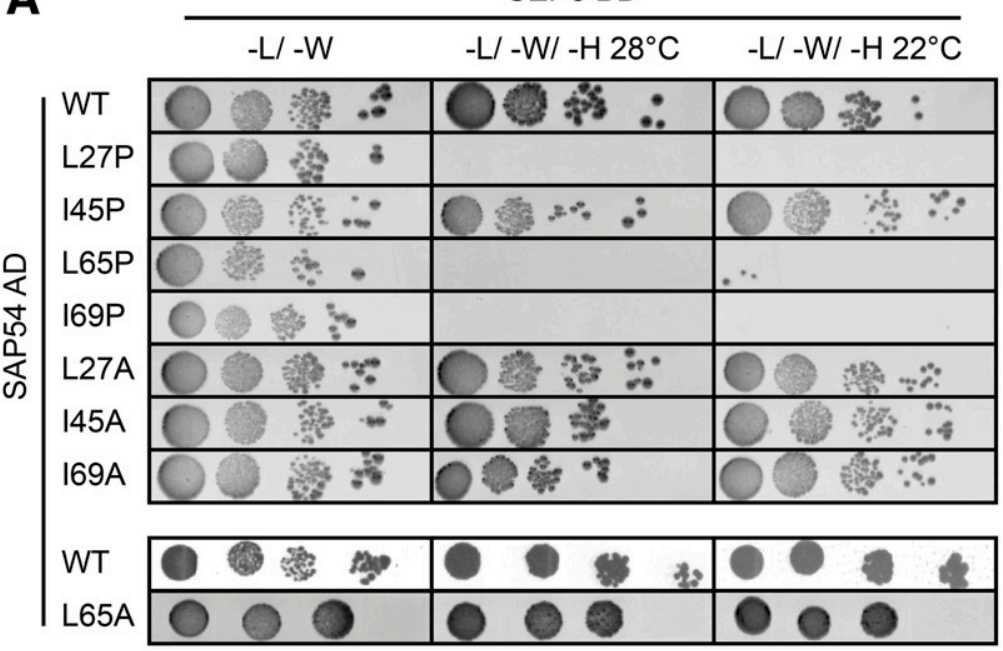
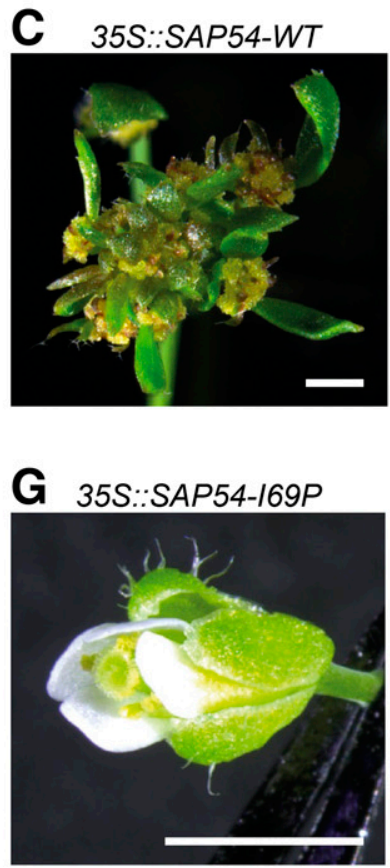

B

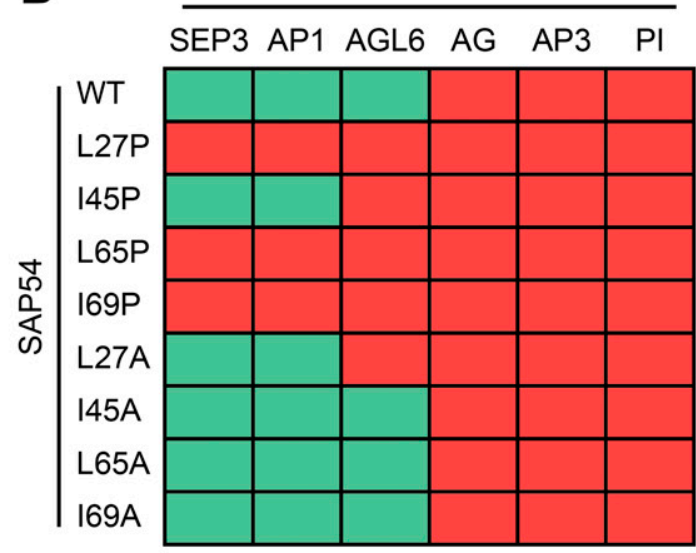

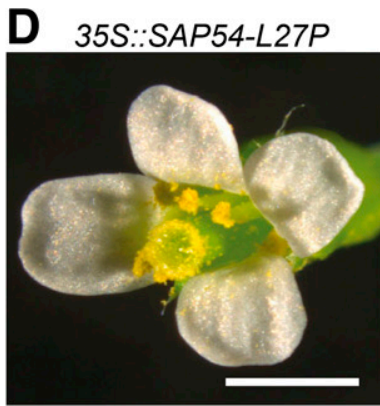

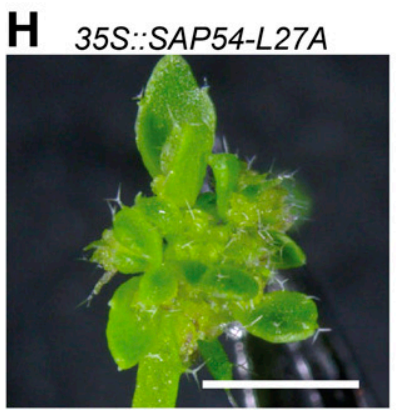

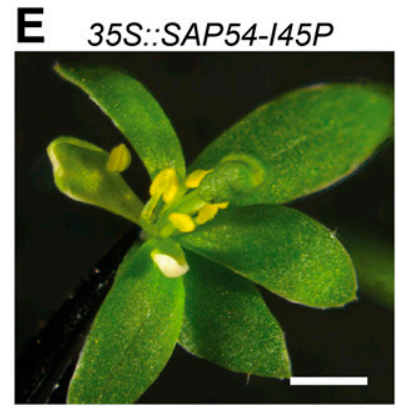
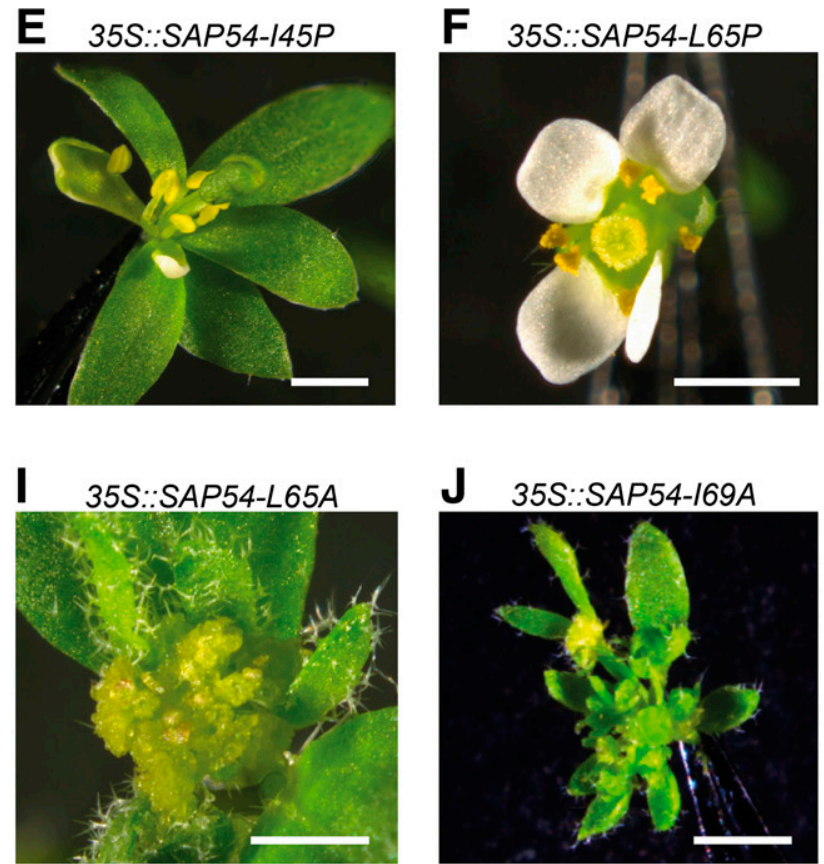

Fig. 4. Interaction capabilities and overexpression phenotypes of SAP54-wt and single amino acid substitution mutants. A, Yeast two-hybrid (Y2H) interaction screen of wild type and mutated versions of SAP54 fused to the activation domain (AD) against SEP3 fused to the binding domain (BD). Normal growth of yeast was controlled on SD-Leu-Trp plates (-L/-W). Interactions were tested on SD-Leu-Trp-His plates with $3 \mathrm{mM} 3$-amino-1,2,4-triazole (-L/-W/-H) at two different temperatures $\left(28\right.$ and $\left.22^{\circ} \mathrm{C}\right)$ and in four dilutions $(1: 10,1: 100,1: 1,000$, and 1:10,000). Another SAP54-AD WT control for SAP54-AD-L65A was added due to the different timepoint of the experimental procedure. B, Summary of Y2H results for SAP54-wt and single amino acid substitution mutants against SEP3, AP1, AGL6, AG, AP3, and PI. Each interaction was tested twice in both directions. A combination was scored as 'interacting' (green) if yeast growth was observed for at least one direction. $\mathbf{C}$ through J, Floral phenotypes of Arabidopsis thaliana plants overexpressing SAP54-wt and single amino acid substitution mutants under control of the cauliflower mosaic virus $35 \mathrm{~S}$ promoter. Scale bars $=1 \mathrm{~mm}$. The incompletely opened flower of the 35S::SAP54-I69P plant $(\mathrm{G})$ does not reflect a phenotypic alteration but very likely is the result of a slightly earlier developmental stage of the flower at the photo acquisition timepoint compared with flowers shown in D and F. Flowers of 35S::SAP54-I69P plants developed like wild type through anthesis and showed no alterations in floral organ outgrowth. 
binding reaction, a supershift was observed (Fig. 5B, lane 2). Since SAP54 does not bind to DNA alone (Fig. 5B, lanes 10 and 12), this demonstrates that SAP54 interacts with SEP3 bound to DNA. Additional EMSA experiments with variable amounts of SEP3 and SAP54 indicate that SEP3 still binds cooperatively to both CArG-boxes even in a complex with SAP54 (Supplementary Fig. S3). Thus, it appears likely that the observed supershift fraction constitutes a DNA-bound SEP3 tetramer directly interacting with at least one SAP54 protein. A SAP54 induced supershift could also be observed if SEP3 $\triangle \mathrm{C}$ (residues 1 to 188 ), which lags the C-terminal domain of SEP3, was used for the binding reaction (Fig. 5B, lanes 3 and 4). In contrast, no supershift was observed if, in addition to the $C$ terminal domain, the $\mathrm{K} 3$-subdomain (SEP3 $\triangle \mathrm{K} 3 \mathrm{C}$, residues 1-152) or the complete $\mathrm{K}$ domain of SEP3 also had been removed (SEP3 $\triangle \mathrm{KC}$, residues 1 to 92 ), indicating that the $\mathrm{K} 3$ subdomain of SEP3 is necessary for the interaction with SAP54, at least if the Cterminal domain is missing (Fig. $5 \mathrm{~B}$, lanes 5 to 8 ).
A
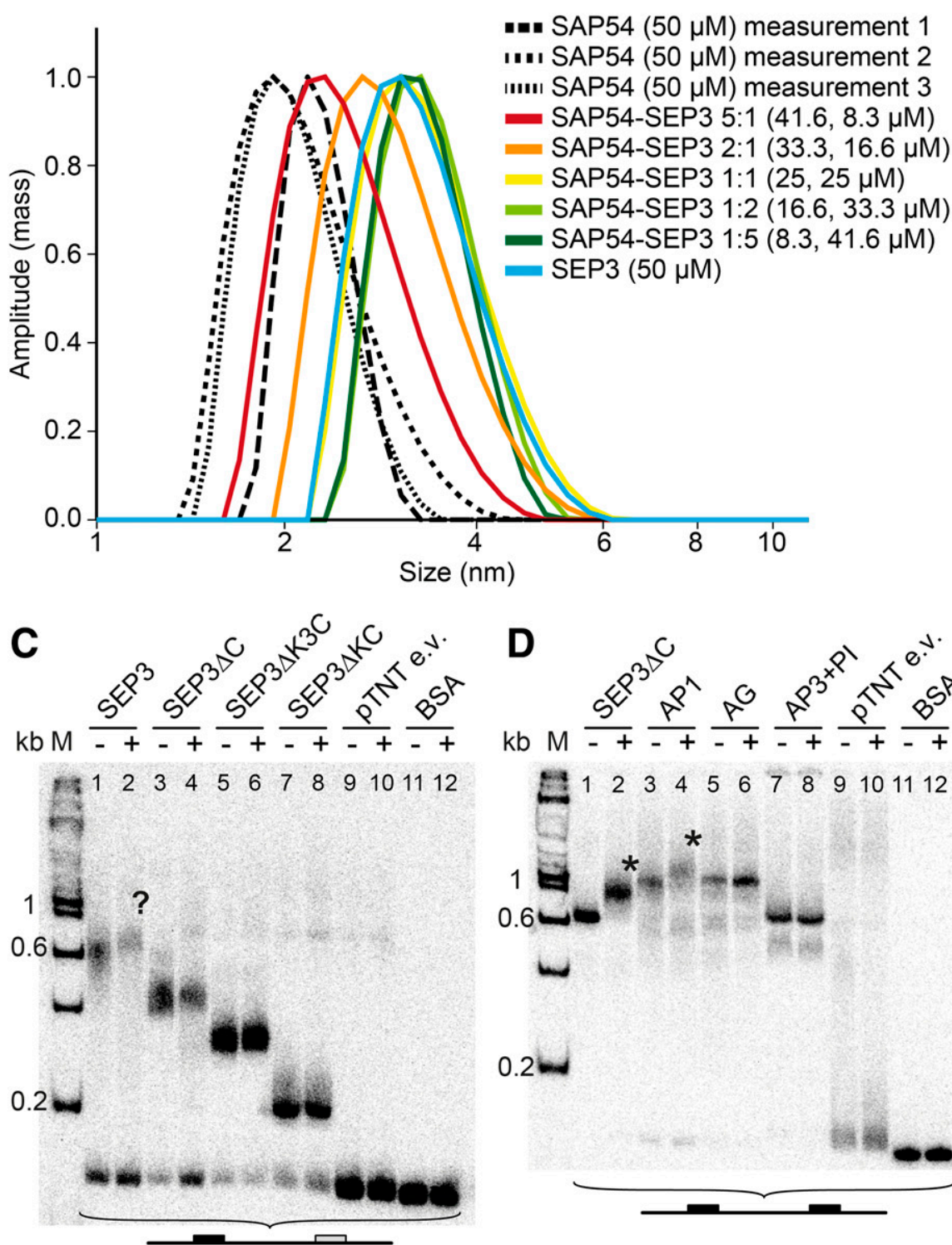

B
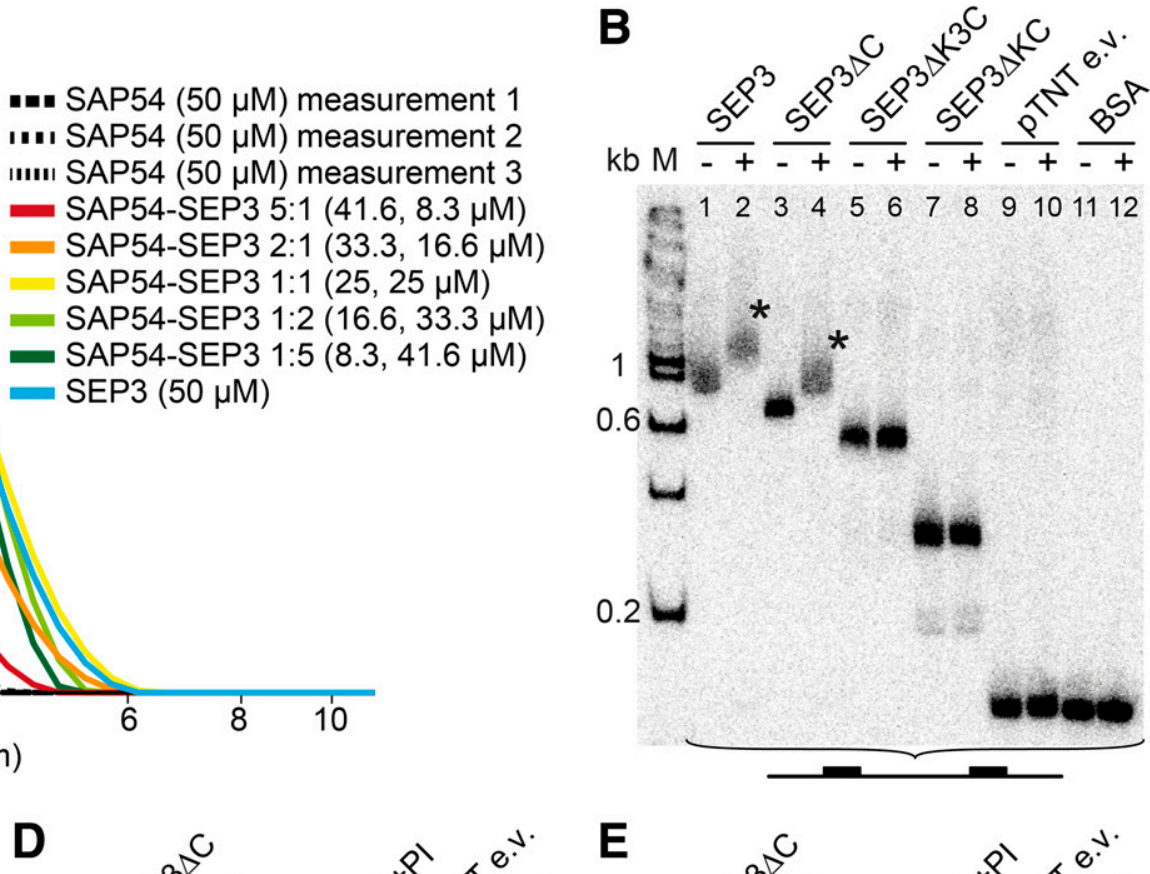

D
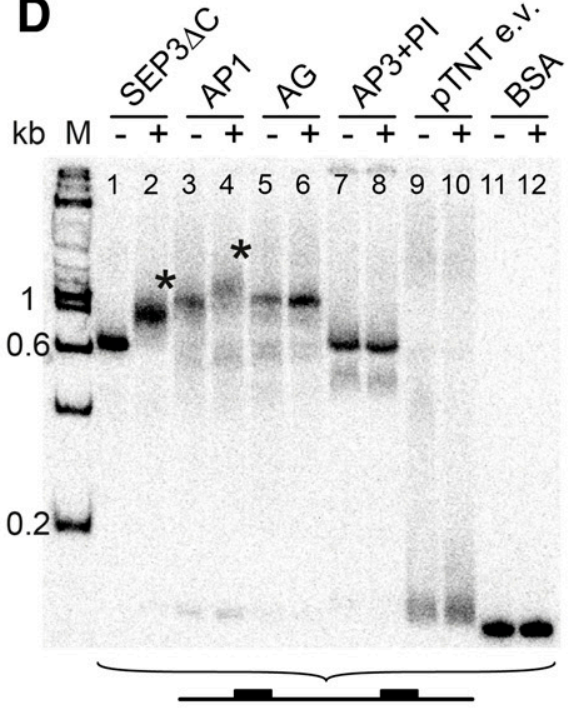

E

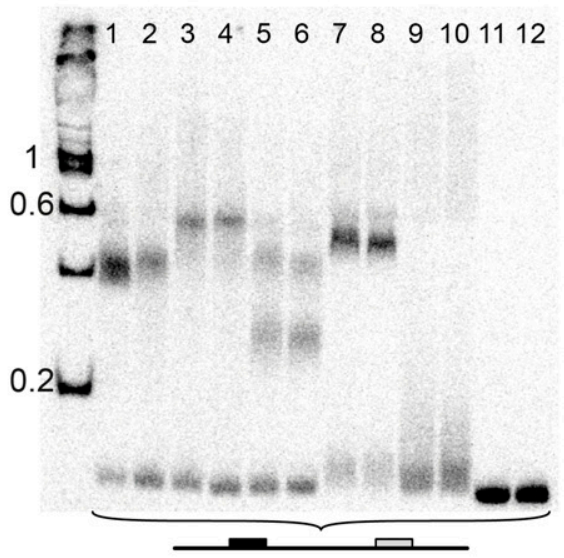

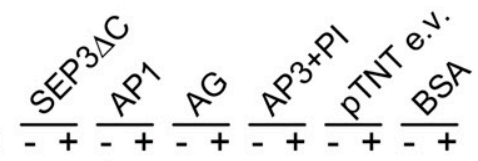

Fig. 5. Dynamic light scattering and electrophoretic mobility shift assays (EMSA) experiments to investigate the stoichiometry of SAP54/MIKC-type MADSdomain transcription factor (MTF) complexes. A, Dynamic light scattering plot (mass-weighted scattering intensity distribution plotted against the size of the hydrodynamic radius in nanometers) of SAP54, SEP $3^{75-178}$, and mixtures of both proteins at different molar ratios. Molarities are based on the monomeric state of the proteins and were determined spectrophotometrically at $280 \mathrm{~nm}$ from extinction coefficients calculated using ProtParam. For SAP54, three biological replicates were measured. B, EMSA in which in vitro-translated SEP3 full-length protein and truncated versions were co-incubated with a radioactively labeled DNA probe carrying two MIKC-type MTF binding sites (CArG-boxes). In lanes labeled with a plus (+), $1 \mu$ of purified SAP54 (13.3 $\mu$ M) was added to the binding reaction. In lanes labeled with a minus (-), $1 \mu \mathrm{l}$ of bovine serum albumin (BSA) (10 mg/ml) was added instead. As negative controls, the empty pTNT vector was used as template for the in-vitro translation (pTNT e.v. lanes) or $30 \mu \mathrm{g}$ of BSA was added instead of in vitro-translated protein (lanes labeled BSA). For size comparison, a radioactively labeled DNA ladder (100 bp DNA Ladder [New England BioLabs]) was applied (lane M). C, With the same setup as in B, using a DNA probe that carries only one CArG-box sequence. D, With the same setup as in B, using the MIKC-type MTFs SEP3 $\triangle \mathrm{C}$, AP1, AG, and the obligate heterodimer AP3/PI together with a DNA probe carrying two CArG-box sequences. E, With the same setup as in D, using a DNA probe that carries only one CArG-box sequence. Asterisks (*) mark supershifts caused by the addition of SAP54. A question mark (?) marks a minor supershift that was observed if SEP3, SAP54, and a DNA probe carrying one CArG-box were co-incubated, probably indicating a weak ability of SAP54 to also target SEP3 dimers. 
If SEP3 was co-incubated with a DNA probe that carries only one CArG-box, a retarded fraction appeared close to the 600-bp fragment of the DNA marker (Fig. 5C, lane 1). Based on previous experiments this fraction constitutes a DNA-bound SEP3 dimer (Jetha et al. 2014; Melzer et al. 2009). Interestingly, neither for DNA bound dimers of SEP3 full-length protein nor for any of the truncated versions was a clear SAP54-induced supershift observed (Fig. 5C, lanes 2 to 8). Taken together, we could show that the presence of SAP54 decreases the electrophoretic mobility of DNA-bound SEP3 tetramers, whereas it does not interfere with the mobility of unbound DNA nor DNA-bound SEP3 dimers. This suggests that SAP54, indeed, preferentially binds to multimers of SEP3 rather than do dimers and thus strongly supports the observations of our dynamic light scattering experiments. Results consistent with this interpretation were obtained for the known SAP54 target AP1 (Fig. 5D and E, lanes 3 and 4), whereas no SAP54 induced supershifts were observed for AG and AP3/PI (Fig. 5D and E, lanes 5 to 8). It should be noted here that, due to a molar excess of MTFs compared with labeled DNA probe (which is required for strong signal intensities of the bound fractions), additional protein complexes of different stoichiometry may coexist in solution.

\section{DISCUSSION}

Employing sequence-based computer predictions, we previously suggested a structure for the phytoplasma effector protein SAP54. It comprises two $\alpha$-helices connected by a short interhelical region containing a conserved proline residue breaking the $\alpha$-helix (Rümpler et al. 2015). The work reported here strongly corroborates our prediction. More comprehensive and detailed in silico secondary structure predictions confirmed that SAP54 is composed of (at least) two putative $\alpha$-helices that are separated by a turn or bend located at the center of the protein sequence. According to the majority of $3 \mathrm{D}$ fold predictions, SAP54 adopts a coiled-coil arrangement of two $\alpha$-helices that are separated by a short interhelical region (Fig. 1 ), very similar to the structure that had been previously hypothesized (Rümpler et al. 2015). In line with this, circular dichroism (CD) spectroscopy of purified protein revealed that SAP54 has an $\alpha$-helical content of about $71 \%$ under our standard condition (Table 1). Only a minor proportion of irregular structure features was found, most likely representing the internal turn and possibly the $\mathrm{N}$ terminus of the protein.

When either of the two putative $\alpha$-helices was removed, SAP54 completely lost its ability to interact with its specific MIKC-type MTF interaction partners in $\mathrm{Y} 2 \mathrm{H}$ experiments (Fig. 3 ). In the case of the C-terminal $\alpha$-helix, even deletion of only the C-terminal 11 residues sufficed to abolish the interaction completely (Fig. 3). In contrast, deletion of the predicted turn in the center of the protein did not result in an altered interaction behavior (Fig. 3). These findings reveal that the two putative $\alpha$-helical regions are required for the interaction of SAP54 with MIKC-type MTFs but that the internal turn is not; they also suggest that the mutual arrangement of the two helices does obviously not matter. The C-terminal 11 residues of SAP54 may comprise an essential binding region for MIKC-type MTFs, although its exact role remains currently unclear. The significant number of evenly spaced conserved leucine and charged residues within this region suggests that it probably mediates strong hydrophobic and electrostatic interactions, as they typically take place between two interacting coiled coils (Mason et al. 2009).

To further test the functional relevance of the predicted structure, we introduced single amino acid substitutions to proline and alanine at different heptad repeat ' $a$ ' and ' $d$ ' leucine/isoleucine positions of the proposed helices of SAP54. When leucine or isoleucine residues near the center of the first (L27) or second (L65, I69) $\alpha$-helix were substituted by the helix-breaking proline, $\alpha$-helical content of the mutant proteins was indeed massively reduced (Fig. 2). Y2H analyses revealed that the mutant proteins were unable to interact with any of the investigated MIKC-type MTFs (Fig. 4). Most importantly, in contrast to the wild-type SAP54, these mutant proteins were not able anymore to cause disease phenotypes such as phyllody when expressed in A. thaliana (Fig. 4). To demonstrate that changes in SAP54 features of the proline substitution mutants was due to the helix-breaking property of proline rather than simply the mutation of crucial interaction sites, we substituted the same residues also with alanines, which do not break helices but could potentially interfere with the interaction of SAP54 with other proteins by way of reducing interaction, owing to the shorter side chain of alanine. However, the respective mutant SAP54 proteins were still able to interact with almost all the tested MIKC-type MTF targets of the wild-type protein in $\mathrm{Y} 2 \mathrm{H}$ experiments, and were still capable to cause disease symptoms when expressed in A. thaliana (Fig. 4). Interestingly, a substitution of isoleucine to proline at position near the C-terminal end of the first putative helix (I45P) showed only a moderate reduction of $\alpha$-helical content (Fig. 2). In line with this mild effect, the interaction with only one of the investigated MIKCtype MTFs was abolished (Fig. 4), and also, accordingly, only a milder phenotypic effect of the mutant protein in causing phyllody was retained, even though, compared with the wildtype protein, its activity was clearly reduced (Fig. 4).

Taken together, our findings suggest a strong causal link between the $\alpha$-helical structure of major parts of SAP54, its

Table 2. Dynamic light scattering results of SAP54, SEP3 ${ }^{75-178}$, and mixtures of both proteins at different molar ratios ${ }^{\mathrm{a}}$

\begin{tabular}{|c|c|c|c|c|c|c|c|}
\hline Proteins & $\mathbf{P k}$ & $\%$ Area & $\mathbf{R h}(\mathbf{n m})$ & Position (nm) & Std Dev & $\%$ RSD & MW (kDa) \\
\hline SAP54 $(50 \mu \mathrm{M})$ sample 1 & 1 & 100 & 2.30 & 2.19 & 0.28 & 12.1 & 23.3 \\
\hline SAP54 $(50 \mu \mathrm{M})$ sample 2 & 1 & 100 & 2.13 & 1.91 & 0.50 & 23.7 & 19.7 \\
\hline SAP54 $(50 \mu \mathrm{M})$ sample 3 & 1 & 100 & 2.07 & 1.91 & 0.38 & 18.4 & 18.4 \\
\hline SEP3 $(50 \mu \mathrm{M})$ & 1 & 100 & 3.32 & 3.09 & 0.65 & 19.7 & 56.2 \\
\hline SAP54-SEP3 1:5 $(8.3,41.6 \mu \mathrm{M})$ & 1 & 100 & 3.35 & 3.09 & 0.49 & 14.7 & 57.8 \\
\hline SAP54-SEP3 1:2 $(16.6,33.3 \mu \mathrm{M})$ & 1 & 100 & 3.43 & 3.31 & 0.54 & 15.8 & 61.0 \\
\hline SAP54-SEP3 1:1 $(25,25 \mu \mathrm{M})$ & 1 & 100 & 3.38 & 3.09 & 0.68 & 20.1 & 58.7 \\
\hline SAP54-SEP3 2:1 $(33.3,16.6 \mu \mathrm{M})$ & 1 & 100 & 3.01 & 2.69 & 0.65 & 21.8 & 44.6 \\
\hline SAP54-SEP3 5:1 (41.6, $8.3 \mu \mathrm{M})$ & 1 & 100 & 2.53 & 2.34 & 0.56 & 22.2 & 29.7 \\
\hline
\end{tabular}

${ }^{\text {a }}$ Molarities are based on the monomeric state of the proteins and were verified spectrophotometrically at $280 \mathrm{~nm}$ with extinction coefficients as derived from ProtParam. $\mathrm{Pk}=$ number of peaks; \% Area = area occupied by this major protein population; $\mathrm{Rh}(\mathrm{nm})=$ hydrodynamic radius; Position $=$ size of the hydrodynamic radius at which peak center occurs; Std Dev = standard deviation of Rh for this peak; \% RSD = percent relative standard deviation of Rh for this peak; MW $(\mathrm{kDa})=$ approximate molecular weight as derived from Rh and assuming a globular shape of the protein in question. For SAP54 three biological replicates were measured. 
ability to interact with some MIKC-type MTFs in Y2H analyses, and its function as an effector protein that causes homeotic transformation of floral organs in planta. All in all, we consider our data as a strong support for our previous hypothesis on the structure of the SAP54 protein and its functional relevance (Rümpler et al. 2015).

While this manuscript was in preparation, Iwabuchi et al. (2019) published the crystal structure of PHYLLOGEN1 $1_{\mathrm{OY}}$ (PHYL1 $1_{\mathrm{OY}}$ ), a homolog of SAP54 from the 'Candidatus Phytoplasma asteris' strain onion yellows (OY). Likewise, Liao et al. (2019) published the crystal structure of PHYL1 $1_{\text {PnWB }}$ from the 'Candidatus Phytoplasma' strain peanut witches' broom. PHYL1 $1_{\text {OY }}$ shares about $87 \%$ sequence identity with SAP54 (Fig. 1A) and generates similar symptoms in planta, suggesting that both proteins work in very similar ways (Maejima et al. 2014). In contrast, PHYL1 $1_{P n W B}$ shares only about $53 \%$ sequence identity with SAP54 and is, hence, probably more distantly related than $\mathrm{PHYL1}_{\mathrm{OY}}$ (Fig. 1A) (Liao et al. 2019). Nevertheless, the crystal structures of both proteins are very similar, comprising two $\alpha$-helices connected by a central linker; they thus corroborate all our conclusions about SAP54 outlined here.

Moreover, Iwabuchi et al. (2019) also reported that mutational changes in the $\alpha$-helices resulted in the loss of phyllodyinducing activity. In contrast to our study of the effects of single amino acid substitutions, Iwabuchi et al. (2019) investigated the consequences of the insertion of amino acid tandems in order to induce rotational shifts in the axes of the $\alpha$-helices. While insertions in either the first or second helix abolished the interaction with some MIKC-type MTFs (SEP1 to SEP4), the degradation of SEP3, and the ability to induce disease symptoms (phyllody), insertion in the linker region had no such effects. Likewise, Liao et al. (2019) reported that some double amino acid substitutions in both, either the first or second helix of PHYL1 $1_{\mathrm{PnWB}}$, abolished the interaction with the K domain of SEP3 in $\mathrm{Y} 2 \mathrm{H}$ experiments. These findings, which are summarized in Figure 6, strongly corroborate all the structurefunction relationships involving SAP54 outlined above.

Taking all three studies together and considering also the high sequence similarity to other homologous proteins (Fig. 1), a much clearer picture of central structural features of SAP54 becomes apparent. It comprises about 90 amino acids that fold into two $\alpha$-helices connected by a short nonhelical connecting segment. SAP54-like proteins may not have a 'rigid' structure, however; to a certain degree, it may depend on environmental conditions, and it may undergo conformational changes upon binding to and release from $\mathrm{K}$ domain (Liao et al. 2019). Also, the functional relevance of the structure for interaction with target proteins and for causing disease phenotypes is now welldocumented (Iwabuchi et al. 2019; this study). These findings will help to better understand the mode of action of SAP54-like proteins in plants.

In fact, our knowledge about the molecular mechanism of SAP54 activity is still quite limited. This applies even to the basics of protein-protein interactions. What, to start with, is the structure of unbound SAP54 and its homomultimers? Iwabuchi et al. (2019) found tetramers of PHYL1 $1_{O Y}$ in the crystals they investigated, but since PHYL1 $1_{\mathrm{OY}}$ did not interact with itself in $\mathrm{Y} 2 \mathrm{H}$ experiments, they concluded that $\mathrm{PHYL} 1_{\mathrm{OY}}$ exists as monomer. It has been shown, however, that $\mathrm{Y} 2 \mathrm{H}$ experiments are biased against the detection of homodimer formation (Newman et al. 2000; Smirnova et al. 1999), so this conclusion does not appear to be cogent. Liao et al. (2019) concluded from sedimentation rates during analytical ultracentrifugation that native PHYL1 $1_{\mathrm{PnWB}}$ exist as a monomer. However, in those experiments, monomers (and tetramers) of $\mathrm{K}$ domain fragments of SEP3 were seen, whereas elsewhere only dimers and tetramers had been detected (Puranik et al. 2014). It could be, therefore, that the conditions during analytical ultracentrifugation have promoted the dissociation of protein complexes. In line with this view, dimers seemed to be present in the crystals assessed by Liao et al. (2019). In fact, employing dynamic light scattering, we found complexes with an apparent molecular mass of approximately $20 \mathrm{kDa}$, suggesting that SAP54 predominantly formed homodimers in solution under our experimental conditions (Fig. 5A, Table 2). However, since the sequence of PHYL1 $1_{\text {PnWB }}$ is quite different from that of SAP54 and PHYL1 $1_{\mathrm{OY}}$ (Fig. 1A), it currently cannot be completely ruled out that $\mathrm{PHYL} 1_{\mathrm{PnWB}}$ has a different interaction behavior, despite the high structural similarity of all three proteins. In any case, one should note that, in all the biophysical analyses described ( $\mathrm{Y} 2 \mathrm{H}$, crystallography, ultracentrifugation), the proteins were under quite artificial conditions that are somewhat different from the cellular milieu in planta (e.g., with respect to

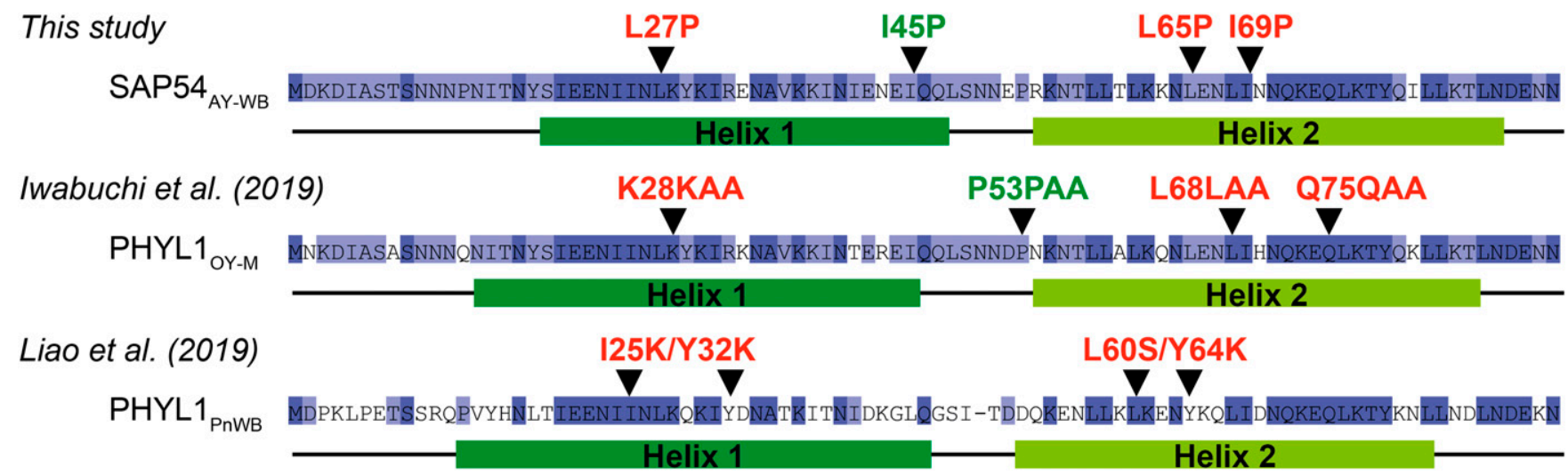

Fig. 6. Comparison of the results of this study and those of Iwabuchi et al. (2019) and Liao et al. (2019). Aligned amino acid sequences of SAP54 from the 'Candidatus phytoplasma asteris' strain aster yellows witches' broom, PHYL1 $1_{\mathrm{OY}}$ from the 'Candidatus phytoplasma asteris' onion yellows strain and PHYL1 $1_{\text {PnWB }}$ from the 'Candidatus Phytoplasma' peanut witches' broom strain. Conserved amino acid positions are marked by blue background color. Single amino acid substitutions to proline of SAP54 performed in this study, double alanine insertions of PHYL1 $1_{\text {OY }}$ performed in Iwabuchi et al. (2019), and double amino acid substitutions of PHYL1 ${ }_{\text {PnwB }}$ performed in Liao et al. (2019) are depicted by black triangles. SAP54/PHYL1 $1_{\mathrm{OY}}$ mutants that did not interact with known MIKC-type MADS-domain transcription factors targets in yeast two-hybrid and that were unable to induce phyllody symptoms when overexpressed in Arabidopsis thaliana are color coded in red, whereas mutants that were still able to induce phyllody are shown in green. Both PHYL1 $1_{\mathrm{PnWB}}$ double amino acid substitution mutants are color coded in red, as they showed no interaction with the K domain of SEP3 in a His-pulldown assay, although PHYL1 PnwB- $^{-}$ I25KY32K to a certain extent was still able to mediate degradation of SEP3, if both proteins were coexpressed in Nicotiana benthamiana. 
concentration and absence of interaction partners). More reliable conclusions about the multimerization of SAP54-like proteins in plant cells, thus, must await additional experiments. Finally, the existence of SAP54-like proteins as monomers, dimers, or tetramers do certainly not represent mutually exclusive scenarios. It would not be too surprising to find dynamic equilibria between the different states in planta.

Little is also known about heteromeric interactions of SAP54. It appears well-established, at least in A. thaliana, that binding of SAP54 to the $\mathrm{K}$ domain of a specific subset of MIKC-type MTFs is a prerequisite for the degradation of these proteins via the UPP (MacLean et al. 2014; Maejima et al. 2014). This binding likely depends on sequence and structural similarity between SAP54 and the K domain, which both fold into $\alpha$-helical structures and contain heptad repeats facilitating the formation of coiled coils, as previously suggested (Rümpler et al. 2015). The similarity between SAP54 and the K domain of MIKC-type MTFs may have originated by convergent evolution during which SAP54 achieved molecular mimicry of the $\mathrm{K}$ domain (Rümpler et al. 2015). More studies on the sequence and structure of SAP54-like proteins in a phylogenetic context are required in the future to clarify the case but are potentially hampered by frequent horizontal transfer of SAP54 genes (Rümpler et al. 2015).

For the sake of simplicity, we have previously suggested that SAP54 may form heterodimeric coiled coils with the K domain of MIKC-type MTFs (Rümpler et al. 2015). In line with this are data, obtained by cross-linking coupled mass spectrometry, suggesting that PHYL1 $1_{\mathrm{PnWB}}$ and the $\mathrm{K}$ domain of SEP3 dimerize via a quadruple-stranded coiled-coil interaction (Liao et al. 2019). However, according to the dynamic light scattering and EMSA results reported here, it now seems more likely that SAP54 preferentially targets multimers of MIKC-type MTFs rather than monomers or dimers (Fig. 5; Supplementary Fig. S3). This observation could probably even help to explain the target specificity of SAP54. For several known targets of SAP54 (SEP1, SEP2, SEP3, and SEP4), it has been shown that they are capable of forming DNA-bound homotetramers (Jetha et al. 2014; Melzer et al. 2009; Rümpler et al. 2018), whereas AP3 and PI that are unable to form homotetramers (Melzer and Theissen 2009; Rümpler et al. 2018) are not bound by SAP54 (MacLean et al. 2014). Whether AP1 can bind to DNA as homotetramer is not entirely clear yet. Assessment of cooperative DNA-binding of AP1 suggests that it might be capable of homotetramerization but with an affinity considerably lower than that determined for SEP3 (data not shown). This might explain why the SAP54 induced supershift is weaker and more blurred in the case of AP1 compared with SEP3, probably indicating a less stable complex. Furthermore, there is evidence that SAP54 binds not only to MIKC-type MTFs but also to RAD23C and RAD23D, i.e., a subset of the RAD23 proteins in A. thaliana (Iwabuchi et al. 2019; MacLean et al. 2014). RAD23 is known to transfer ubiquitylated substrates to the $26 \mathrm{~S}$ proteasome (Farmer et al. 2010), so SAP54 may just function as an adapter that connects MIKC-type MTFs with RAD23 proteins to deliver them to the proteasome (MacLean et al. 2014). The exact place and mode of RAD23 binding to SAP54 is unknown; however, several models have been proposed in which MIKC-type MTFs and RAD23 bind simultaneously or, alternatively, to SAP54 (MacLean et al. 2014). $\alpha$-Helical coiled coils are versatile protein domains that can contain more than two $\alpha$-helices in parallel or antiparallel direction (Lupas and Gruber 2005), and RAD23 proteins have a high content of $\alpha$-helical structure (Farmer et al. 2010; Hurley et al. 2006). Thus, it is conceivable that not only SAP54 and MIKC-type MTFs may form a multimeric coiled-coil structure, but probably even RAD23 can be incorporated in such a complex.
Future analyses of complexes of SAP54 with either K domains, RAD23 proteins, or both by nuclear magnetic resonance or $\mathrm{X}$-ray diffraction may clarify the case.

\section{MATERIALS AND METHODS}

\section{Sequence collection, multiple sequence alignment, and structure predictions.}

The sequence collection of SAP54 orthologs was compiled via nucleotide BLAST searches (Altschul et al. 1990) against the NCBI nucleotide collection and whole as well as partial genome sequences of diverse phytoplasma strains (Supplementary Table S2), using the CDS of SAP54 from AY-WB as query sequence. The nucleotide sequences were translated into the encoded amino acid sequences using EXPASY translate (Gasteiger et al. 2003) and were subsequently aligned with MAFFT (Katoh and Standley 2013), applying L-INS-I mode. Secondary and 3D structure predictions were performed using PCOILS (Lupas et al. 1991), PSIPRED (McGuffin et al. 2000), Jpred4 (Drozdetskiy et al. 2015), SCRATCH protein predictor (Cheng et al. 2005), QUARK Online (Xu and Zhang 2012), and SWISS-MODEL (Waterhouse et al. 2018).

\section{Cloning of SAP54 and $S E P 3^{75-178}$}

The CDSs of the secreted part of SAP54 from aster yellows witches' broom phytoplasma (CP000061.1, AYWB_224) and SEP3 (NM_102272.4) K domain (amino acids 75 to 178) were codon optimized for expression in E. coli K12 with JCAT (Grote et al. 2005) and synthesized by Thermo Fisher Scientific (Supplementary Table S3). Restriction sites for NdeI and BamHI were introduced at the beginning and end of the CDSs. The synthesized sequences were amplified via PCR and were cloned into the pET-15b expression vector (Novagen), using NdeI and BamHI restriction sites, to create expression constructs with an N-terminal 6-His tag followed by a thrombin cleavage site (pET-15b-SAP54, pET-15b-SEP3 ${ }^{75-178}$ ). Mutated versions of SAP54 were constructed by site-directed mutagenesis (Zheng et al. 2004).

\section{Expression and purification of SAP54 and SEP3 ${ }^{\text {75-178 }}$.}

For protein expression, E. coli Tuner (DE3) cells (Novagen) were transformed with pET-15b-SAP54 and pET-15b$S E P 3^{75-178}$, using heat-shock transformation. Cells were grown in Luria-Bertani medium containing $100 \mu \mathrm{g}$ of ampicillin per milliliter at $37^{\circ} \mathrm{C}$ and $180 \mathrm{rpm}$. An overnight culture was used to inoculate prewarmed medium $(1: 10)$, which was then grown to an optical density at $600 \mathrm{~nm}\left(\mathrm{OD}_{600}\right)$ of 0.5 . The culture was centrifuged, resuspended, and added to new medium until $\mathrm{OD}_{600}=0.8$. Protein expression was induced by the addition of $0.5 \mathrm{mM}$ isopropyl-beta-D-1-thiogalactopyranoside. Cells were harvested $3 \mathrm{~h}$ after induction by centrifugation at $5,000 \times g$ at $4{ }^{\circ} \mathrm{C}$ for $20 \mathrm{~min}$. For purification, cells were resuspended in lysis buffer (50 mM Tris, pH 8.0, $300 \mathrm{mM} \mathrm{NaCl}, 5 \mathrm{mM}$ imidazole) and one tablet cOmplete protease inhibitor cocktail (Roche). The cells were lysed and homogenized by ultrasonification and French press disintegration. The debris was centrifuged at $15,400 \times g$ at $4^{\circ} \mathrm{C}$ for $30 \mathrm{~min}$. Supernatant was applied twice to a column containing a gel bed of $2 \mathrm{ml}$ of nickel-nitriloacetic acid agarose (Qiagen) equilibrated with lysis buffer. The column was then washed with one column volume of lysis buffer, washing buffer $(20 \mathrm{mM}$ Tris, $\mathrm{pH} 8.0,300 \mathrm{mM} \mathrm{NaCl}, 20 \mathrm{mM}$ imidazole), and, finally, with high salt buffer (50 mM Tris, $\mathrm{pH}$ $8.0,500 \mathrm{mM} \mathrm{NaCl}$ ). Elution of the His-tagged proteins was performed using $50 \mathrm{mM}$ Tris, $\mathrm{pH} 8.0,300 \mathrm{mM} \mathrm{NaCl}$, and $250 \mathrm{mM}$ imidazole. Fractions were pooled, were supplemented with thrombin protease ( $5 \mathrm{U}$ per milligram of protein [Merck]), and were dialyzed against dialysis buffer $(10 \mathrm{mM}$ Tris, $\mathrm{pH} 8.0$, 
$150 \mathrm{mM} \mathrm{NaCl}$ ) overnight at $4^{\circ} \mathrm{C}$. Success of the thrombin cleavage was verified via sodium dodecyl sulfate-polyacrylamide gel electrophoresis (SDS-PAGE). The protein without His tag was concentrated using a Vivaspin 20 Ultrafiltration Unit (3 $\mathrm{kDa}$ molecular weight cutoff [Sartorius]). An appropriate volume was applied to a 1-ml loop of a gel filtration column (Superdex75 10/300 GL, GE Healthcare) of an Äkta Avant System (GE Healthcare). Protein fractions were assessed by SDS-PAGE and fractions of interest were pooled and concentrated to $100 \mu \mathrm{M}$.

\section{CD spectra collection.}

The purified protein was diluted to $20 \mu \mathrm{M}$ in $20 \mathrm{mM}$ sodium phosphate buffer, $\mathrm{pH}$ 8.0. Protein concentration was determined spectrophotometrically at $280 \mathrm{~nm}$, with extinction coefficients calculated by ProtParam $\left(\varepsilon\right.$ SAP54 and $\varepsilon$ SEP3 $\left.3^{75-178}=4,470\right)$. CD spectra (range of 190 to $260 \mathrm{~nm}, 20 \mathrm{~nm}$ per minute, $1 \mathrm{~nm}$ slit width and a response time of $2 \mathrm{~s}$ ) of freshly prepared protein solutions were recorded with five scans per spectrum, using a JASCO J-710 CD spectropolarimeter (Jasco) at $20^{\circ} \mathrm{C}$ in a $1-\mathrm{mm}$ path length quartz cuvette. Background subtraction was carried out using a blank CD spectrum of $20 \mathrm{mM}$ sodium phosphate buffer, $\mathrm{pH}$ 8.0. The raw spectra were processed using the CAPITO web server application (Wiedemann et al. 2013). For melting curves, the temperature was increased stepwise by $5^{\circ} \mathrm{C}$ from 20 to $90^{\circ} \mathrm{C}$. Temperature increase was with a slope of $1^{\circ} \mathrm{C}$ per minute, the sample was kept at target temperature for $5 \mathrm{~min}$ before the CD spectra were recorded using the same parameters described above.

\section{Dynamic light scattering.}

Dynamic light scattering of SAP54 and SEP3 ${ }^{75-178}$ were carried out in a Viscotek 802 DLS device (Malvern Panalytical) equipped with a $50-\mathrm{mW}$ fiber-coupled $830-\mathrm{nm}$ diode laser. For each protein solution, 50 accumulated experiments $(5 \mathrm{~s}$ each) were recorded at $20^{\circ} \mathrm{C}$ in a $50-\mu$ l volume. Protein concentrations were in the range of 8 to $50 \mu \mathrm{M}$ in $20 \mathrm{mM}$ sodium phosphate buffer, $\mathrm{pH}$ 8.0. Mass-weighted distribution of hydrodynamic radii and a model of globular proteins were utilized to convert hydrodynamic radii to molecular weights. Data acquisition and processing was carried out using the OmniSIZE 3.0 software (Malvern Panalytical).

\section{Y2H screen.}

The CDSs of the secreted part of SAP54-wt and mutated versions as well as the full-length CDSs of the MTFs SEP3, AP1, AGL6, AP3, and PI were cloned into plasmids pGADT7 and pGBKT7. The Y2H screen was performed as described by Wang et al. (2010), with the following deviations: one additional -Leu/-Trp/-His plate was incubated at $28^{\circ} \mathrm{C}$ for each interaction series and interaction was scored after 5 to 7 days of incubation. Additionally, the $\beta$-galactosidase assay was performed on -Leu/-Trp plates. An individual interaction was scored when growth on both interaction plates (at 22 and $28^{\circ} \mathrm{C}$ ) and blue coloration of the colonies in the $\beta$-galactosidase assay was observed. Each protein pair was tested twice in both directions. A protein pair was scored as 'interacting' if yeast growth was observed for at least one direction in both replicates.

\section{Yeast protein extraction and Western blot.}

The expression of SAP54-wt and mutant versions as well as MIKC-type MTFs in yeast cells was confirmed by protein extraction according to the protocol of Kushnirov (2000), followed by SDS-PAGE, Western blot, and immuno-detection using monoclonal antibodies raised in mouse against the GAL4 activation or binding domain (1:10,000 dilution) (Clontech), following the Matchmaker Monoclonal Antibodies user manual from Clontech. An antibody against $\alpha$-tubulin $(1: 10,000 \mathrm{di}-$ lution) (abcam) was used as a loading control for protein extracts. Proteins were detected using the Roti-Lumin kit (CarlRoth) and were visualized in the ImageQuant LAS 4000mini (GE Healthcare).

\section{Plant transformation and phenotyping.}

For SAP54 overexpression studies in A. thaliana Col0 plants, the CDS of the secreted part of SAP54-wt and mutant versions were cloned into the pGreen0229 vector under control of the CaMV $35 \mathrm{~S}$ promoter. The vectors were used to transform Agrobacterium tumefaciens GV3101 cells (carrying the helper plasmid pSOUP) via electroporation at $1,800 \mathrm{~V}$, using the Electroporator 2510 (Eppendorf). Agrobacteria were screened via colony PCR using primers flanking the 35S promoter region and the terminator region of the T-DNA. Correct clones were used for floral-dipping, following a published protocol (Clough and Bent 1998). Plants were covered with plastic bags to retain moisture for $24 \mathrm{~h}$. After maturity seeds were collected and sown on soil. The herbicide BASTA $(0.001 \%)$ (Bayer) was applied via spraying to select transformed $\mathrm{T} 1$ seedlings. T1 plants were grown under long-day conditions at $22^{\circ} \mathrm{C}$ and were phenotyped using the z-stack function of a Leica M205 FA microscope (Leica).

\section{Plant protein extraction and Western blot.}

For protein extraction from transformed plants, $80 \mathrm{mg}$ of leaf and inflorescence material were ground to a fine powder over $40 \mathrm{~s}$ at $30 \mathrm{~Hz}$ at $4^{\circ} \mathrm{C}$, using the Retsch MM 400 Mill (Thermo Fischer Scientific), and were then resuspended in $200 \mu \mathrm{l}$ of homogenization buffer (0.1 M Tris-HCL, pH 7.5, $10 \%$ glycerol, $5 \mathrm{mM}$ EDTA, $2 \mathrm{mM}$ EGTA, $2 \mathrm{mM}$ phenylmethylsulfonyl fluoride, $40 \mathrm{mM} \beta$-mercaptoethanol, $2 \mu \mathrm{g}$ of pepstatin per milliliter, $2 \mu \mathrm{g}$ of leupeptin per milliliter). The solution was centrifuged for $3 \mathrm{~min}$ at $16,000 \times g$ at $4^{\circ} \mathrm{C}$ and supernatant was used for Western blot as described above. Primary antibody against SAP54 (raised in rabbit, provided by S. Hogenhout, John-Innes Centre) was used in a 1:2,000 dilution.

\section{In vitro translation and EMSA.}

In vitro translation and EMSA were performed essentially as described by Melzer et al. (2009). The plasmids for in vitro translation of $A$. thaliana SEP3, SEP3 $\triangle \mathrm{C}$ (amino acids 1 to 188 ), SEP3 $\triangle \mathrm{K} 3 \mathrm{C}$ (amino acids 1 to 152 ), SEP3 $\triangle \mathrm{KC}$ (amino acids 1 to 92), AP1, AP3, PI, and AG, namely pTNTSEP3, pTNT-SEP3 $\triangle \mathrm{C}$, pTNT-SEP3 $\triangle \mathrm{K} 3 \mathrm{C}$, pTNT-SEP3 $\triangle \mathrm{KC}$, pSPUTK-AP1, pSPUTK-AP3, pSPUTK-PI, and pSPUTK-AG had been generated and described previously (Melzer et al. 2009; Riechmann et al. 1996). DNA probe preparation and labeling had also been described previously (Melzer et al. 2009). The CArG-box sequence (5'-CCAAATAAGG-3') used for probe preparation was derived from the regulatory intron of A. thaliana AG. To test for binding of SAP54 to DNA-bound MIKC-type MTF tetramers a 151-bp DNA probe was used that contained two CArG-box sequences in a distance of $63 \mathrm{bp}$, i.e., six helical turns (sequence: 5'-TCGAG GTCGG AAATT TAATT ATATT $C C A A A T A A G G$ AAAGT ATGGA ACGTT CGACG GTATC GATAA GCTTG ATGAA ATTTA ATTAT ATTCC AAATA AGGAA AGTAT GGAAC GTTAT CGAAT TCCTG CAGCC CGGGG GATCC ACTAG TTCTA G-3'; CArG-box sequences are in italics). To test for binding of SAP54 to DNA-bound MIKC-type MTF dimers, a DNA probe was used in which one of the two CArG-boxes and its flanking regions were exchanged by a random sequence of the same base composition (sequence: 5' -TCGAG GTCGA TAAAA CGGCA AGGAG AATTA TATTT TTATG ATGAA CATAT CGACG 
GTATC GATAA GCTTG ATGAA ATTTA ATTAT ATTCC AAATA AGGAA AGTAT GGAAC GTTAT CGAAT TCCTG CAGCC CGGGG GATCC ACTAG TTCTA G-3'). The composition and final concentrations of the protein-DNA binding reaction buffer were $1.6 \mathrm{mM}$ EDTA, $10.3 \mathrm{mM}$ HEPES, $1 \mathrm{mM}$ dithiothreitol, $1.3 \mathrm{mM}$ spermidine hydrochloride, $33.3 \mathrm{ng}$ of Poly dI/dC per microliter, $2.5 \%$ CHAPS, $4.3 \%$ glycerol, and $3.72 \mu \mathrm{g}$ of bovine serum albumin (BSA) per microliter. For each binding reaction, $0.1 \mathrm{ng}$ of labeled DNA probe were coincubated with $3 \mu \mathrm{l}$ of in vitro-translated MIKC-type protein and either $1 \mu \mathrm{l}$ of purified SAP54 $(13.3 \mu \mathrm{M})$ or $1 \mu \mathrm{l}$ of BSA $(10 \mu \mathrm{g} / \mu \mathrm{l})$ overnight at $4^{\circ} \mathrm{C}$. The co-operative DNA-binding assay shown in Supplementary Figure S3 was performed essentially as described by Melzer et al. (2009). A constant amount of $0.1 \mathrm{ng}$ of labeled DNA probe containing two CArGboxes was co-incubated with variable amounts of in vitrotranslated SEP $3 \Delta \mathrm{C}$, ranging from 0.05 to $2 \mu \mathrm{l}$. After measuring the relative signal intensities of all fractions for each lane, using Multi Gauge 3.1 (Fujifilm), the ability of SEP3 $\triangle \mathrm{C}$ to cooperatively bind to two DNA-binding sites was quantified, using equations as previously described (Melzer et al. 2009; Senear and Brenowitz 1991). To examine whether SEP3 $\Delta$ C still binds co-operatively to DNA in the presence of SAP54, the same assay was performed while adding $1 \mu \mathrm{l}$ of purified SAP54 $(13.3 \mu \mathrm{M})$ to each binding reaction.

\section{ACKNOWLEDGMENTS}

We thank S. Hogenhout (John Innes Centre, Norwich, U.K.) for sharing unpublished data, insightful discussions and kindly providing anti-SAP54 antibody. We are also grateful to S. Häfner (Fritz Lipmann Institute, Jena, Germany) for her skillful assistance in the purification of proteins.

\section{AUTHOR-RECOMMENDED INTERNET RESOURCES}

CAPITO web server: capito.uni-jena.de

JCAT tool: http://www.jcat.de

ProtParam tool: https://web.expasy.org/protparam

\section{LITERATURE CITED}

Altschul, S. F., Gish, W., Miller, W., Myers, E. W., and Lipman, D. J. 1990. Basic local alignment search tool. J. Mol. Biol. 215:403-410.

Bai, X., Correa, V. R., Toruño, T. Y., Ammar, D., Kamoun, S., and Hogenhout, S. A. 2009. AY-WB phytoplasma secretes a protein that targets plant cell nuclei. Mol. Plant-Microbe Interact. 22:18-30.

Bendtsen, J. D., Nielsen, H., von Heijne, G., and Brunak, S. 2004. Improved prediction of signal peptides: SignalP 3.0. J. Mol. Biol. 340:783-795.

Bertaccini, A. 2007. Phytoplasmas: diversity, taxonomy, and epidemiology. Front. Biosci. 12:673-689.

Cheng, J., Randall, A. Z., Sweredoski, M. J., and Baldi, P. 2005. SCRATCH: A protein structure and structural feature prediction server. Nucleic Acids Res. 33:W72-W76.

Christensen, N. M., Axelsen, K. B., Nicolaisen, M., and Schulz, A. 2005 Phytoplasmas and their interactions with hosts. Trends Plant Sci. 10: 526-535.

Clough, S. J., and Bent, A. F. 1998. Floral dip: A simplified method for Agrobacterium-mediated transformation of Arabidopsis thaliana. Plant J. 16:735-743.

Cunningham, B. C., and Wells, J. A. 1989. High-resolution epitope mapping of hGH-receptor interactions by alanine-scanning mutagenesis. Science 244:1081-1085.

de Folter, S., Immink, R. G., Kieffer, M., Parenicová, L., Henz, S. R., Weigel, D., Busscher, M., Kooiker, M., Colombo, L., Kater, M. M., Davies, B., and Angenent, G. C. 2005. Comprehensive interaction map of the Arabidopsis MADS Box transcription factors. Plant Cell 17: 1424-1433.

Drozdetskiy, A., Cole, C., Procter, J., and Barton, G. J. 2015. JPred4: A protein secondary structure prediction server. Nucleic Acids Res. 43: W389-W394.

Du Toit, A. 2014. Phytoplasma converts plants into zombies. Nat. Rev. Microbiol. 12:393.
Farmer, L. M., Book, A. J., Lee, K. H., Lin, Y. L., Fu, H., and Vierstra, R. D. 2010. The RAD23 family provides an essential connection between the $26 \mathrm{~S}$ proteasome and ubiquitylated proteins in Arabidopsis. Plant Cell 22: 124-142.

Firrao, G., Garcia-Chapa, M., and Marzachì, C. 2007. Phytoplasmas: Genetics, diagnosis and relationships with the plant and insect host Front. Biosci. 12:1353-1375.

Gasteiger, E., Gattiker, A., Hoogland, C., Ivanyi, I., Appel, R. D., and Bairoch, A. 2003. ExPASy: The proteomics server for in-depth protein knowledge and analysis. Nucleic Acids Res. 31:3784-3788.

Grote, A., Hiller, K., Scheer, M., Münch, R., Nörtemann, B., Hempel, D. C., and Jahn, D. 2005. JCat: A novel tool to adapt codon usage of a target gene to its potential expression host. Nucleic Acids Res. 33: W526-W531

Hogenhout, S. A., Oshima, K., Ammar, D., Kakizawa, S., Kingdom, H. N., and Namba, S. 2008. Phytoplasmas: Bacteria that manipulate plants and insects. Mol. Plant Pathol. 9:403-423.

Hoshi, A., Oshima, K., Kakizawa, S., Ishii, Y., Ozeki, J., Hashimoto, M., Komatsu, K., Kagiwada, S., Yamaji, Y., and Namba, S. 2009. A unique virulence factor for proliferation and dwarfism in plants identified from a phytopathogenic bacterium. Proc. Natl. Acad. Sci. U.S.A. 106 6416-6421.

Hurley, J. H., Lee, S., and Prag, G. 2006. Ubiquitin-binding domains. Biochem. J. 399:361-372.

Immink, R. G., Tonaco, I. A., de Folter, S., Shchennikova, A., van Dijk, A. D., Busscher-Lange, J., Borst, J. W., and Angenent, G. C. 2009 SEPALLATA3: The 'glue' for MADS box transcription factor complex formation. Genome Biol. 10:R24.

Iwabuchi, N., Maejima, K., Kitazawa, Y., Miyatake, H., Nishikawa, M., Tokuda, R., Koinuma, H., Miyazaki, A., Nijo, T., Oshima, K., Yamaji, Y. and Namba, S. 2019. Crystal structure of phyllogen, a phyllody-inducing effector protein of phytoplasma. Biochem. Biophys. Res. Commun. 513: 952-957.

Jetha, K., Theißen, G., and Melzer, R. 2014. Arabidopsis SEPALLATA proteins differ in cooperative DNA-binding during the formation of floral quartet-like complexes. Nucleic Acids Res. 42:10927-10942.

Kakizawa, S., Oshima, K., Kuboyama, T., Nishigawa, H., Jung, H., Sawayanagi, T., Tsuchizaki, T., Miyata, S., Ugaki, M., and Namba, S. 2001. Cloning and expression analysis of Phytoplasma protein translocation genes. Mol. Plant-Microbe Interact. 14:1043-1050.

Katoh, K., and Standley, D. M. 2013. MAFFT multiple sequence alignment software version 7: Improvements in performance and usability. Mol. Biol. Evol. 30:772-780.

Kaufmann, K., Melzer, R., and Theissen, G. 2005. MIKC-type MADSdomain proteins: Structural modularity, protein interactions and network evolution in land plants. Gene 347:183-198.

Kelly, S. M., Jess, T. J., and Price, N. C. 2005. How to study proteins by circular dichroism. Biochim. Biophys. Acta 1751:119-139.

Kempin, S. A., Savidge, B., and Yanofsky, M. F. 1995. Molecular basis of the cauliflower phenotype in Arabidopsis. Science 267:522-525.

Kükenshöner, T., Wohlwend, D., Niemöller, C., Dondapati, P., Speck, J., Adeniran, A. V., Nieth, A., Gerhardt, S., Einsle, O., Müller, K. M., and Arndt, K. M. 2014. Improving coiled coil stability while maintaining specificity by a bacterial hitchhiker selection system. J. Struct. Biol. 186: 335-348.

Kushnirov, V. V. 2000. Rapid and reliable protein extraction from yeast. Yeast 16:857-860.

Lee, I. M., Davis, R. E., and Gundersen-Rindal, D. E. 2000. Phytoplasma: Phytopathogenic mollicutes. Annu. Rev. Microbiol. 54:221-255.

Liao, Y. T., Lin, S. S., Lin, S. J., Sun, W. T., Shen, B. N., Cheng, H. P., Lin, C. P., Ko, T. P., Chen, Y. F., and Wang, H. C. 2019. Structural insights into the interaction between phytoplasmal effector causing phyllody 1 (PHYL1) and MADS transcription factor. Plant J. 100:706-719.

Liu, J., Gopurenko, D., Fletcher, M. J., Johnson, A. C., and Gurr, G. M. 2017. Phytoplasmas-The "crouching tiger" threat of Australian plan pathology. Front. Plant Sci. 8:599.

Lupas, A., Van Dyke, M., and Stock, J. 1991. Predicting coiled coils from protein sequences. Science 252:1162-1164.

Lupas, A. N., and Gruber, M. 2005. The structure of alpha-helical coiled coils. Adv. Protein Chem. 70:37-38.

Ma, H., Yanofsky, M. F., and Meyerowitz, E. M. 1991. AGL1-AGL6, an Arabidopsis gene family with similarity to floral homeotic and transcription factor genes. Genes Dev. 5:484-495.

MacLean, A. M., Orlovskis, Z., Kowitwanich, K., Zdziarska, A. M., Angenent, G. C., Immink, R. G., and Hogenhout, S. A. 2014. Phytoplasma effector SAP54 hijacks plant reproduction by degrading MADS-box proteins and promotes insect colonization in a RAD23dependent manner. PLoS Biol. 12:e1001835. 
MacLean, A. M., Sugio, A., Makarova, O. V., Findlay, K. C., Grieve, V. M., Tóth, R., Nicolaisen, M., and Hogenhout, S. A. 2011. Phytoplasma effector SAP54 induces indeterminate leaf-like flower development in Arabidopsis plants. Plant Physiol. 157:831-841.

Maejima, K., Iwai, R., Himeno, M., Komatsu, K., Kitazawa, Y., Fujita, N., Ishikawa, K., Fukuoka, M., Minato, N., Yamaji, Y., Oshima, K., and Namba, S. 2014. Recognition of floral homeotic MADS domain transcription factors by a phytoplasmal effector, phyllogen, induces phyllody. Plant J. 78:541-554.

Maejima, K., Kitazawa, Y., Tomomitsu, T., Yusa, A., Neriya, Y., Himeno, M., Yamaji, Y., Oshima, K., and Namba, S. 2015. Degradation of class E MADS-domain transcription factors in Arabidopsis by a phytoplasmal effector, phyllogen. Plant Signal. Behav. 10:e1042635.

Mason, J. M., and Arndt, K. M. 2004. Coiled coil domains: Stability, specificity, and biological implications. ChemBioChem 5:170-176.

Mason, J. M., Hagemann, U. B., and Arndt, K. M. 2009. Role of hydrophobic and electrostatic interactions in coiled coil stability and specificity. Biochemistry 48:10380-10388.

McGuffin, L. J., Bryson, K., and Jones, D. T. 2000. The PSIPRED protein structure prediction server. Bioinformatics 16:404-405.

Melzer, R., and Theissen, G. 2009. Reconstitution of 'floral quartets' in vitro involving class $\mathrm{B}$ and class $\mathrm{E}$ floral homeotic proteins. Nucleic Acids Res. 37:2723-2736.

Melzer, R., Verelst, W., and Theissen, G. 2009. The class E floral homeotic protein SEPALLATA3 is sufficient to loop DNA in 'floral quartet'-like complexes in vitro. Nucleic Acids Res. 37:144-157.

Moitra, J., Szilák, L., Krylov, D., and Vinson, C. 1997. Leucine is the most stabilizing aliphatic amino acid in the $d$ position of a dimeric leucine zipper coiled coil. Biochemistry 36:12567-12573.

Morrison, K. L., and Weiss, G. A. 2001. Combinatorial alanine-scanning. Curr. Opin. Chem. Biol. 5:302-307.

Newman, J. R. S., Wolf, E., and Kim, P. S. 2000. A computationally directed screen identifying interacting coiled coils from Saccharomyces cerevisiae. Proc. Natl. Acad. Sci. U.S.A. 97:13203-13208.

Nilsson, I., Sääf, A., Whitley, P., Gafvelin, G., Waller, C., and von Heijne, G. 1998. Proline-induced disruption of a transmembrane alpha-helix in its natural environment. J. Mol. Biol. 284:1165-1175.

Puranik, S., Acajjaoui, S., Conn, S., Costa, L., Conn, V., Vial, A., Marcellin, R., Melzer, R., Brown, E., Hart, D., Theißen, G., Silva, C. S., Parcy, F., Dumas, R., Nanao, M., and Zubieta, C. 2014. Structural basis for the oligomerization of the MADS domain transcription factor SEPALLATA3 in Arabidopsis. Plant Cell 26:3603-3615.

Ranjbar, B., and Gill, P. 2009. Circular dichroism techniques: Biomolecular and nanostructural analyses-A review. Chem. Biol. Drug Des. 74:101-120.

Richardson, J. S. 1981. The anatomy and taxonomy of protein structure. Adv. Protein Chem. 34:167-339.

Riechmann, J. L., Krizek, B. A., and Meyerowitz, E. M. 1996. Dimerization specificity of Arabidopsis MADS domain homeotic proteins APETALA1, APETALA3, PISTILLATA, and AGAMOUS. Proc. Natl. Acad. Sci. U.S.A. 93:4793-4798

Rümpler, F., Gramzow, L., Theißen, G., and Melzer, R. 2015. Did convergent protein evolution enable phytoplasmas to generate 'zombie plants'? Trends Plant Sci. 20:798-806.
Rümpler, F., Theißen, G., and Melzer, R. 2018. A conserved leucine zipperlike motif accounts for strong tetramerization capabilities of SEPALLATAlike MADS-domain transcription factors. J. Exp. Bot. 69:1943-1954.

Senear, D. F., and Brenowitz, M. 1991. Determination of binding constants for cooperative site-specific protein-DNA interactions using the gel mobility-shift assay. J. Biol. Chem. 266:13661-13671.

Smaczniak, C., Immink, R. G. H., Angenent, G. C., and Kaufmann, K. 2012a. Developmental and evolutionary diversity of plant MADS-domain factors: Insights from recent studies. Development 139:3081-3098.

Smaczniak, C., Immink, R. G. H., Muiño, J. M., Blanvillain, R., Busscher, M., Busscher-Lange, J., Dinh, Q. D., Liu, S., Westphal, A. H., Boeren, S. Parcy, F., Xu, L., Carles, C. C., Angenent, G. C., and Kaufmann, K. 2012b. Characterization of MADS-domain transcription factor complexes in Arabidopsis flower development. Proc. Natl. Acad. Sci. U.S.A. 109:1560-1565.

Smirnova, E., Shurland, D. L., Newman-Smith, E. D., Pishvaee, B., and van der Bliek, A. M. 1999. A model for dynamin self-assembly based on binding between three different protein domains. J. Biol. Chem. 274: 14942-14947.

Sugio, A., Kingdom, H. N., MacLean, A. M., Grieve, V. M., and Hogenhout, S. A. 2011a. Phytoplasma protein effector SAP11 enhances insect vector reproduction by manipulating plant development and defense hormone biosynthesis. Proc. Natl. Acad. Sci. U.S.A. 108: E1254-E1263.

Sugio, A., MacLean, A. M., Kingdom, H. N., Grieve, V. M., Manimekalai, R., and Hogenhout, S. A. 2011b. Diverse targets of phytoplasma effectors: From plant development to defense against insects. Annu. Rev. Phytopathol. 49:175-195.

Theißen, G., Melzer, R., and Rümpler, F. 2016. MADS-domain transcription factors and the floral quartet model of flower development: Linking plant development and evolution. Development 143:3259-3271.

Uversky, V. N. 2002. Natively unfolded proteins: A point where biology waits for physics. Protein Sci. 11:739-756.

Wang, Y. Q., Melzer, R., and Theissen, G. 2010. Molecular interactions of orthologues of floral homeotic proteins from the gymnosperm Gnetum gnemon provide a clue to the evolutionary origin of 'floral quartets'. Plant J. 64:177-190.

Waterhouse, A., Bertoni, M., Bienert, S., Studer, G., Tauriello, G., Gumienny, R., Heer, F. T., de Beer, T. A. P., Rempfer, C., Bordoli, L., Lepore, R., and Schwede, T. 2018. SWISS-MODEL: Homology modelling of protein structures and complexes. Nucleic Acids Res. 46 (W1):W296-W303.

Wiedemann, C., Bellstedt, P., and Görlach, M. 2013. CAPITO-A web server-based analysis and plotting tool for circular dichroism data. Bioinformatics 29:1750-1757.

$\mathrm{Xu}$, D., and Zhang, Y. 2012. Ab initio protein structure assembly using continuous structure fragments and optimized knowledge-based force field. Proteins 80:1715-1735.

Zhang, J., Hogenhout, S. A., Nault, L. R., Hoy, C. W., and Miller, S. A. 2004. Molecular and symptom analyses of phytoplasma strains from lettuce reveal a diverse population. Phytopathology 94:842-849.

Zheng, L., Baumann, U., and Reymond, J. L. 2004. An efficient one-step site-directed and site-saturation mutagenesis protocol. Nucleic Acids Res. 32:e115. 